\title{
Modelling the performance of wind-hydrogen energy systems: case study the Hydrogen Office in Scotland/UK.
}

VALVERDE-ISORNA, L., ALI, D., HOGG, D. and ABDEL-WAHAB, M. 


\title{
Modelling the performance of wind-hydrogen energy systems: Case study the Hydrogen Office in Scotland/UK
}

\author{
L. Valverde-Isorna ${ }^{a, n}$, D. Alib , D. Hogg c, M. Abdel-Wahab ${ }^{d}$ \\ a Departamento de Ingeniería Energética, Escuela Técnica Superior de Ingeniería, Universidad de Sevilla, Seville, Spain \\ b Electrical and Computer Engineering, Texas A\&M University in Qatar, Doha, Qatar \\ c Bright Green Hydrogen, The Hydrogen Office, Ajax Way, Scotland, UK \\ d School of the Built Environment, Heriot-Watt University, Edinburgh, Scotland, UK \\ *Corresponding author. Tel.: +34 954482250. \\ E-mail addresses: lvalverde@etsi.us.es (L. Valverde-Isorna), dallia.ali@qatar.tamu.edu (D. Ali), david.hogg@thehydrogenoffice.com (D. Hogg), m.abdel- \\ wahab@hw.ac.uk (M. Abdel-Wahab).
}

\section{A b s t r a c t}

The "Hydrogen Office building (HO)" presents a wind-hydrogen energy system, located in Fife/Scotland, which has been set-up to demonstrate the role of hydrogen in reducing the impact of wind intermittency in a grid-tied microgrid. The main components of the system are a wind turbine, alkaline electrolyser, hydrogen storage and a PEM fuel cell. The building demand is met by the wind turbine, while the fuel cell provides back-up power to the ground floor when wind power is unable to meet the demand.

Accurate modelling of wind-hydrogen systems allows their successful implementation and operation, however, most of the currently available simulation tools do not provide consistent methods to represent the dynamic behaviour of such systems which is essential for their precise design, control, performance optimisation and economic study. Previous research lacks global methodologies for a whole-system scope simulation. Moreover, experimental validation is missing in most of these models and no guidelines are given for parameter estimation, which are essential for replicability.

This paper presents a comprehensive methodology for the modelling, simulation and performance evaluation of wind-hydrogen systems, while including experimental validation and guidelines for parameters estimation. The developed model encompasses usability, adaptability, dominant dynamics accuracy and reliability that makes it able to assess different systems prior and after their installation. The proposed model has succeeded to depict the HO dynamic behaviour accurately with an error of less than $2 \%$ in average.

The model has also been successfully utilised to evaluate the HO system performance. Evaluation criteria includes: average energy production, stand-alone operation and round-trip efficiency among others. Quantitative analysis has showed how this methodology can contribute to improve the design and performance of such systems.

Keywords:

Wind-hydrogen; Dynamic modelling; Experimental validation; Simulation; Renewable energy grid integration; Fuel cells

\section{Introduction}

Investment in renewable energy sources (RES) is at the centre of Energy policy in Europe. However, intermittency of RES's can pose a risk to the security of energy supply and thus energy storage becomes essential to address the mismatch between energy demand and supply. Although there is a wide range of technologies that can enable the storage of large quantities of energy, for example heat storage [1,2], cold storage [3], or the most common hydropower, hydrogen storage presents interesting advantages. Hydrogen, as an energy storage medium, can deliver a fuel to produce clean power through a fuel cell with water and heat as the by-products. Hydrogen can also be injected into the gas grid or can be used as an energy carrier stored and delivered where needed. $\mathrm{H}_{2}$ as a storage medium has about three times the specific energy as for the same weight of oil. Furthermore, hydrogen has the potential for downstream applications such as car fuelling, fertilizer production, metallurgy, electrical generation and high \& low grade heat applications. Furthermore, hybrid renewable $\mathrm{H}_{2}$ energy systems that employ fuel cells can be a solution for addressing the mismatch between energy demand and supply [4].

Recent investment in demonstration projects across Europe that combines renewable energy, hydrogen storage and fuel cells in both grid-connected and remote applications has taken place to accelerate the progress of application of Fuel Cells where excess green power is stored in the form of hydrogen to be utilised later. Wind energy in particular is a promising technology for power generation, which has gone through tremendous development in the last decade. Several wind-hydrogen $\left(\mathrm{Wind} / \mathrm{H}_{2}\right)$ demonstration projects have been installed and studied in the recent years to examine the viability of hydrogen as a storage medium for wind energy. An overview of the most relevant Wind/ $\mathrm{H}_{2}$ demonstration systems and pilot plants installed around the world in the last decade is provided in Table 1. A complete list of such projects together with a technical evaluation of their operation can be found in literature [5-7]. 
In this context, modelling of such Wind/H2 systems plays a significant role in understanding their performance and their impact when connected to the grid. System design, sizing, technoeconomic analysis, study of possible control strategies and optimisation are some of the examples where modelling could assist in the successful implementation and operation of such systems.

Despite of the advantages of mathematical modelling, there are still many obstacles to overcome. Wind/H2 systems are composed of a variety of equipment using different technologies with a wide range of dynamics and disciplines (electrical, chemical, thermal, etc.). Therefore, modelling such a system to mathematically describe this multidisciplinary environment is a complex theoretical and practical problem that requires a more structured and systematic definition and exploration of methodologies. Models range from simple power-in power-out to complex non-linear differential equations. Dynamic models are useful because the mathematical underpinning needed for simulation requires theory to be precise to describe time evolution. Dynamic simulation allows visualising the complex interactions in the system when they are all active at the same time in a global model, and this is what occurs in a real system. Furthermore, it allows for examining a variety of scenarios to see how they play out on the long run. The bottom line for the model is to be able to identify the cause behind any potential deviation from the expected behaviour, and suggest solutions to solve the problem.

Very few references to date have been able to properly address the accurate modelling of Wind/ $\mathrm{H}_{2}$ systems. A stand-alone windhydrogen model has been developed by Pedrazzi [13] to simulate the system behaviour over an annual time frame for residential use. Khan et al. [14] focused their study on a small Wind/ $\mathrm{H}_{2}$ sys-tem in which the presented simulations represent the plant behaviour in the time frame of milliseconds and seconds; the dynamic interaction between the system components has also been considered. Onar [15] presented the power electronic models within the renewable hybrid system in the time frame of seconds. The charging and discharging dynamics of high pressure hydrogen storage has been considered by Raju [16], where simulations has been performed for a residential Wind/H2 system. Tao Zhou [17] presented the modelling of hydrogen production in a control oriented model. A renewable energy laboratory from "The Hydrogen Research Institute" (Trois-Rivières, Canada) has been modelled in [18], in which empirical relationships have been employed for modelling each component and lab characterisation of all equipment has been used to obtain the model parameters. In the same way, a lab-scale hydrogen microgrid is modelled in [19]. A hybrid multi-source energy system has been modelled in [20] to analyse the system behaviour. The control strategy has been tested in the model before experimental implementation.

In existing literature, there are two contrasting approaches for the global simulation of Wind/H2 systems. First, the long-term approach which runs on a monthly, or yearly basis and it is used for the preliminary designing/sizing of such systems. To carry out such simulations, static models are used and long step sizes (normally, one-hour intervals, during which, the system parameters remain constant) are considered. The second approach is to use very accurate models for the individual equipment. However, due to the complexity and the number of parameters involved in such models, they are therefore employed for short-term simulations in the order of seconds.

Table 1

Wind-hydrogen demo projects around the world.

\begin{tabular}{lllll}
\hline Project & Country & Configuration & Year & Reference \\
\hline Utsira & Norway & Grid-connected & 2004 & {$[8,9]$} \\
HARI & U.K. & Stand-alone & 2004 & {$[10]$} \\
ITHER & Spain & Grid-connected & 2005 & {$[11]$} \\
RES2H2 & Greece & Grid-connected & 2005 & {$[11]$} \\
PURE & U.K. & Stand-alone & 2005 & {$[12]$} \\
SOTAVENTO & Spain & Grid-connected & 2007 & {$[11]$} \\
RES2H2 & Spain & Grid-connected & 2007 & {$[11]$} \\
Prince Edward Island Project & Canada & Stand-alone & 2008 & {$[11]$} \\
HIDROLICA & Spain & Grid-connected & 2009 & {$[11]$} \\
Ramea Island Project & Canada & Grid-connected & 2010 & {$[11]$} \\
Hydrogen Office & U.K. & Grid-connected & 2010 & {$[8]$} \\
Hybrid Power Plant Enertrag, & Germany & Grid-connected & 2011 & {$[7]$} \\
\multicolumn{1}{l}{ Prenzlau } & & & & \\
\hline
\end{tabular}




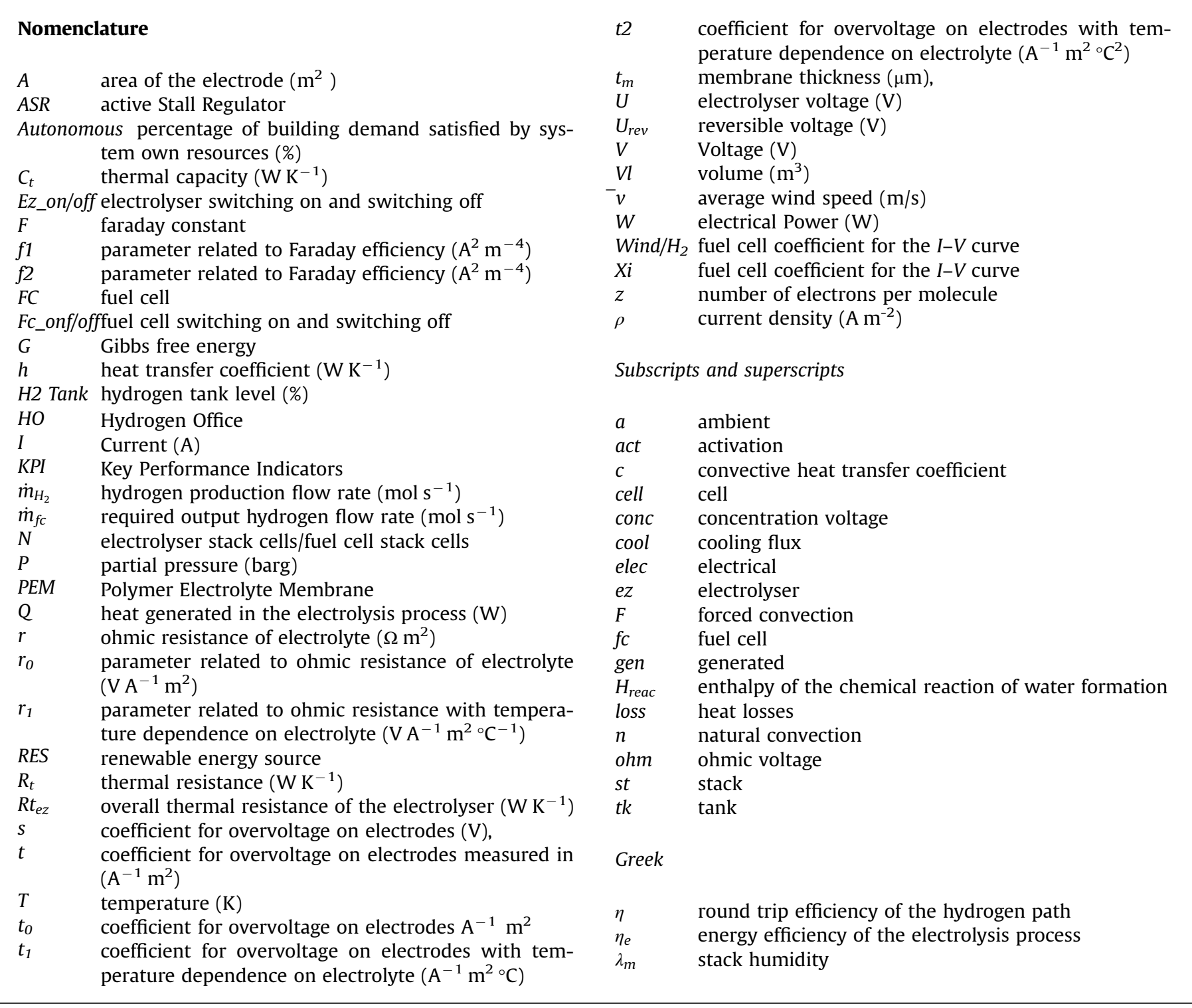

The approaches presented in literature to date are not useful in analysing the dynamic behaviour and system optimisation of the Wind/H2 systems for medium term (several days), since static models present significant errors while accurate models for the wind turbine, electrolyser or fuel cell are too computationally demanding for such simulation periods. Static models common limitation is that they miss the thermal dynamic effects, despite of the fuel cell and electrolyser transient operation being better described by thermal dynamic modelling. Specifically, the equipment operation temperature and thermodynamics effects influence their performance strongly [21]. Experimental validation of the models presented in literature is another common weak point. There are no papers presenting the validation of the whole system, only validation of individual equipment models can be found like: validating the Phoebus solar plant's electrolyser [22], or validating the electrolyser model by means of experimental data [21] and the validation of PEM fuel cell stacks [23,24]. Vali-dation of a complete Wind/H2 system model is a complicated process in which most of the model parameters, such as thermal capacity, overvoltage potential, cell area, etc., are unknown. Additionally, for different reasons, papers often lack guidelines/methodologies to address modelling and simulation of a real-scale system outside the lab environment. Among these reasons, is the reality that after a decade of demonstration projects, very few projects have published consistent operational data [6]. More extensive monitoring of the systems is required for the modelling and validation tasks as stated by the International Energy Agency (IEA) [5]. The lack of experimental data can be attributed either to confidentiality or system unreliability. Moreover real system con-straints, BoP and multi-physic dynamics have not yet been han-dled in detail. 
It can be concluded that so far, the modelling and validation of a complete Wind/ $\mathrm{H}_{2}$ system has not yet been properly addressed. To the best of the author's knowledge, the works presented in literature are not useful to simulate the complete $\mathrm{Wind} / \mathrm{H}_{2}$ system dynamics. Previous research has focused on providing specific solutions for each application, without providing consistent methods for whole system level simulation. Taking a global view approach to develop a modelling methodology enables top-down modelling, which begins by considering the system at top level and proceeds through the further system details.

By taking a global view, the models encompasses usability, adaptability, dominant dynamics, reliability (validation) and constraints as they exist in real Wind/ $\mathrm{H}_{2}$ systems. By incorporating information feedback within the model, the internal variables and external outputs are combined to generate prediction of the model dynamics at a given initial conditions.

This article addresses the aforementioned requirements by: presenting a real world $\mathrm{Wind} / \mathrm{H}_{2}$ system in operation; identifying its major components and their integration in a workable system; proposing a complete modelling methodology which encompasses dominant dynamics accuracy and usability; developing a metho-dology to obtain the parameters of the main equipment of $\mathrm{Wind} / \mathrm{H}_{2}$ systems and validate the models; enabling the complete system simulations in a numerical software environment (Matlab-Simu-link) to generate results; assessing the system performance based on key performance indicators; finally, providing an in-deep ana-lysis and discussion of the results to draw conclusions.

The paper main contribution is developing a comprehensive mathematical model that considers the thermal dynamic, multi-physical and non-linearity effects for the multi-design and analysis purposes of real-scale Wind/ $\mathrm{H}_{2}$ systems. The proposed model is implemented

and fully validated in Matlab-Simulink ${ }^{\mathrm{S}}$ which allows modular construction and complex simulations. The presented implementation also allows the model expansion if necessary. In the proposed model, a trade-off between usability and accuracy is achieved.

A quantitative analysis of system performance is discussed. The presented methodology will be useful for future research involving modelling, design, control or optimisation of similar systems, as well as for their economic perfor-mance analysis.

The rest of the paper is organised as follows: Section 2 over-views the considered case study "The Hydrogen Office Demonstration Project" and its system components while Section 3 describes the proposed modelling approach. Parameters for the developed-models are then obtained using the methodology proposed in Section 4 together with the recorded data of the HO system as a case study; the individual models are also experimentally validated in this section. The operation of the overall Hydrogen Office' Wind/H2 system under different scenarios is then covered in Section 5, providing an analysis and discussion of the HO performance. Finally, Section 6 summarizes the main conclusions of the work done and the recommended future work.

\section{Overview of the Hydrogen Office demonstration project}

The HO' wind-hydrogen energy system has been chosen here as the case study for modelling, since it is close to state of the art, and its data are available for use. In this system, the renewable energy resource (wind energy) is directly used to feed the load when available, while the surplus is stored in the form of hydrogen to be used in a fuel cell to meet a proportion of the buildings' needs during periods when wind is unable to meet demand.

The HO system includes a wind turbine, an electrolyser, a hydrogen storage tank and a fuel cell in a single AC microgrid unit interconnected with the utility grid (all specifications are given in Table 2). Power electronics (inverters and rectifiers) are used to adapt the voltage/current values to the AC link. The system also contains a ground source heat pump. For clarity, a simple diagram of how this microgrid is set-up is shown in Fig. 1.

During normal operation the wind turbine provides enough electricity to meet the whole building demand. A robustness-oriented control system detects the excess in wind energy and the available empty space in the hydrogen storage tank in order to determine when to switch on the electrolyser. The remaining excess wind generation is exported to the grid. At times of little or no wind, the stored hydrogen is fed into the fuel cell to provide electricity for the ground floor offices. The Hydrogen Office is connected to the national grid to allow power import and export when necessary. The grid connection increases system reliability, e.g. in case of system overhaul or emergency as it adds a backup energy supply. Also powered from the HO system is an electric-van that is equipped with lead-acid batteries that are charged by either the wind turbine or by the fuel cell. The stated range of the van is $40-60$ miles.

The system has autonomy of around 2 weeks. It is very unlikely that the office will ever rely solely on grid electricity, as the probability of having 2 weeks with little or no wind is minimal at this coastal location. A wind energy assessment was carried out prior to the installation of the wind turbine. This assessment had over-estimated the amount of on-site wind by around $10 \%$ com-pared to the actual yield from the turbine.

The rationale for sizing of the hydrogen system was based on meeting the electrical needs of only the ground floor of the Hydrogen Office building, where the "Bright Green Hydrogen" (the company who owns the system) is located, and not on feeding all the electrical needs of the whole building. For this reason, the fuel cell was designed to only feed the ground floor offices in the building. The electrolyser and storage were designed so that the tank could be filled in one day and have the capacity to run the offices from the fuel cell for 10 working days (between 9 a.m. and 5 p.m. on weekdays), while keeping an overall aim of keeping costs low but allowing the company to have a firm financial foundation. The turbine was oversized to allow the sale of excess electricity to the grid and increase the system profitability. 
Table 2

HO system components specifications.

\begin{tabular}{lll} 
System component & Rated capacity & Manufacturer \\
\hline Wind turbine & $750 \mathrm{~kW}$ & Global wind power \\
Alkaline electrolyser & $30 \mathrm{~kW}_{\mathrm{e}}$ & Erre Due \\
Storage & $11 \mathrm{~kg} \mathrm{@} 12 \mathrm{bar}$ & - \\
PEM fuel cell & $2 \times 5 \mathrm{~kW}$ & Altergy \\
Building & $30 \mathrm{~kW}$ Peak & - \\
\hline
\end{tabular}

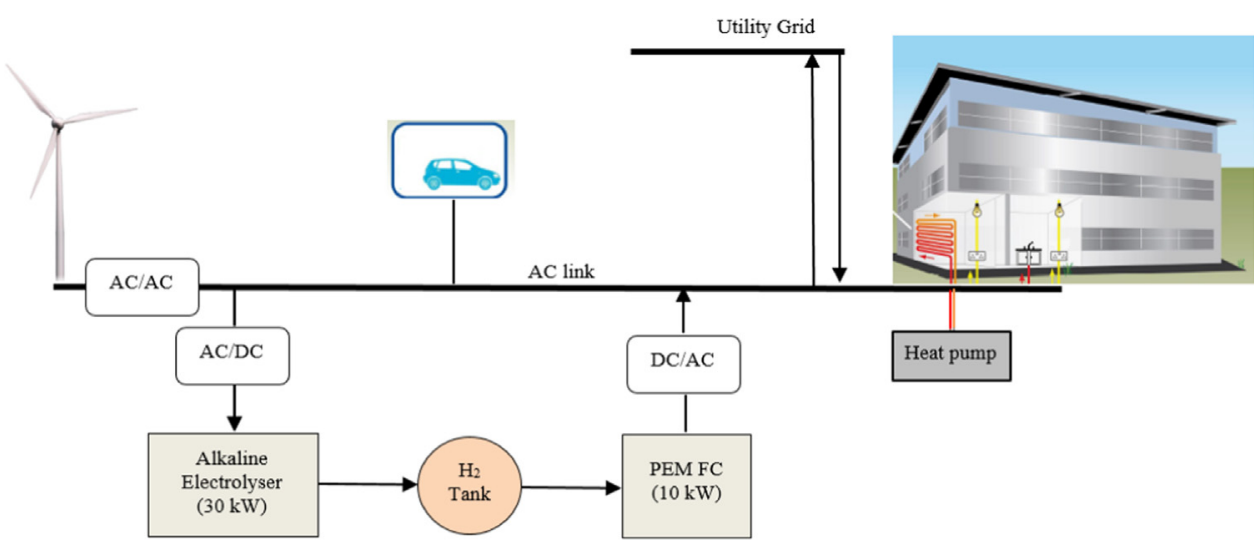

Fig. 1. The $\mathrm{H}_{2}$ Office system comprising wind turbine, alkaline electrolyser, pressurised tank, fuel cell and electric vehicle.

\subsection{Wind turbine}

The GWP47-750 kW wind turbine used in the HO is an ASR (Active stall regulation) wind turbine with rotor diameter of $47 \mathrm{~m}$. The turbine uses LM 21.0P blades from LM Glasfiber. The blades can be turned to obtain optimal operational settings at both low and high wind speeds. ASR wind turbines utilise the best characteristics of both stall and pitch regulated wind turbines, it has the same regulation potential as a pitch regulated turbine; but by using the stall properties of the blades, the large load and power fluctuations that are typical for a pitch regulated machine are avoided.

The turbine produces on average more than of $3300 \mathrm{kWh}$ of electricity per day, equivalent to half the annual consumption of a typical four bedroom home. This value was obtained from the actual amount of electricity produced by the turbine in one year divided by the number of days per year. The power curve provided by the manufacturer is shown in Fig. 2 . The GWP47 main features are summarised in Table 3.

\subsection{Alkaline electrolyser}

An alkaline electrolyser is a type of electrolyser where the electrolyte is an alkaline solution (typically $\mathrm{KOH} 30 \mathrm{wt} \%$ ). The $\mathrm{HO}$ electrolyser has a maximum power input of $30 \mathrm{~kW}$, with a nominal hydrogen production of $5.33 \mathrm{Nm}^{3} / \mathrm{h}$ and an oxygen production of 2.6 $\mathrm{Nm}^{3} / \mathrm{h}$. The alkaline technology has been selected because of its maturity, cost and availability in the market. The outlet hydrogen delivering pressure is 12 barg, reaching a purity of $99.3-99.8 \%$. A Deoxo purification system is located downstream in order to reach a purity of $99.995 \%$. The electrolyser comprises two $15 \mathrm{~kW}$ stacks each composed of 90 cells connected in series. Its average performance efficiency is around $50 \%$ referred to low heating value. A deionised water unit is placed before the electrolyser to achieve water conductivity of $5 \mathrm{mS}$. The electrolyser is switched on only when the turbine production is more than $80 \mathrm{~kW}$ on average for $10 \mathrm{~min}$. The electrolyser does not then need to follow the electricity production of the turbine at low power levels. This results in less stress being placed on the electrolyser unit, and accordingly a longer lifetime. The electrolyser specifications are presented in the Table 4. 


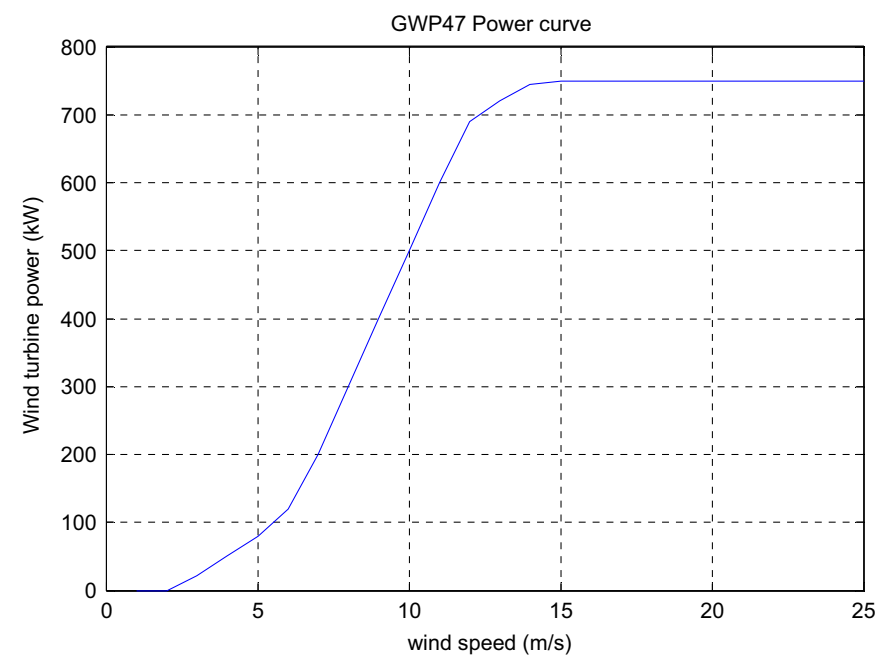

Table 3

Wind turbine GWP47 characteristics.

\begin{tabular}{ll}
\hline Characteristic & Value \\
\hline Cut in speed & $4 \mathrm{~m} / \mathrm{s}$ \\
Cut out speed & $25 \mathrm{~m} / \mathrm{s}$ \\
Rated speed & $12 \mathrm{~m} / \mathrm{s}$ \\
Rated power & $750 \mathrm{~kW}$ \\
\hline
\end{tabular}

Fig. 2. GWP47-750 kW power curve.

\subsection{Hydrogen gas storage vessel}

The hydrogen produced by the electrolyser is stored without further compression in a stainless-steel tank (outside the HO building). Thereby, the maximum tank filling pressure is 12 barg (the electrolyser delivery pressure) although the tank design pressure is 33 barg. Thus, the total tank storage capacity is $11 \mathrm{~kg}$ of hydrogen. This approach avoids the cost and energy losses of adding a compressor, increasing the overall plant efficiency. It has to be mentioned that the tank can be isolated from the rest of the system in case of an emergency so that the hydrogen stored in the tank is not lost. It should be noticed also that not all the hydrogen in the tank is used; a minimum threshold of $30 \%$ of the tank capacity is needed to activate the fuel cell for safe operation.

Table 4

ERRE DUE $30 \mathrm{~kW}$ alkaline electrolyser technical specifications.

\begin{tabular}{ll}
\hline Alkaline electrolyser & Rated value \\
\hline Power & $2 \times 15 \mathrm{~kW}$ \\
Operation range & $20-100 \%$ \\
Voltage operation range & $240-420 \mathrm{~V}$ \\
Current operation rage & $25-71 \mathrm{~A}$ \\
Pressure & $12 \mathrm{barg}$ \\
$\mathrm{H}_{2}$ production & $5.33 \mathrm{Nm}^{3} \mathrm{~h}^{-1}$ \\
Electrolyte & $\mathrm{KOH} \mathrm{30 \%}$ \\
Operation temperature & $80{ }^{\circ} \mathrm{C}$ \\
Cells & $2 \times 90$ \\
Electrode cell area & $0.06 \mathrm{~m}^{2}$
\end{tabular}

Table 5

PEMFC SYSTEM technical specifications.

\begin{tabular}{ll}
\hline PEM FC & Value \\
\hline Power & $2 \times 5 \mathrm{~kW}$ \\
Operation range & $0-100 \%$ \\
Voltage operation range & $240-420 \mathrm{~V}$ \\
Current operation rage & $25-71 \mathrm{~A}$ \\
$\mathrm{H}_{2}$ consumption @ rated power & $0.8 \mathrm{Nm}^{3} \mathrm{~kW} \mathrm{~h}^{-1}$ \\
Membrane thickness & $178 \mu \mathrm{m}$ \\
Oxygen partial pressure & $0.21 \mathrm{barg}$ \\
Hydrogen partial pressure & $3 \mathrm{barg}$ \\
Stack humidity & 14 \\
Number of Cells & $2 \times 50$ \\
$\mathrm{E}^{0}$ Potential at unity activity & $1.229 \mathrm{~V}$ \\
\hline
\end{tabular}

\subsection{PEM fuel cell system}

A $10 \mathrm{~kW}$ PEM fuel cell (PEMFC) system, manufactured by Altergy Systems, composed of two $5 \mathrm{~kW}$ stacks each with 50 cells is installed at the HO. The PEM FC is auto-humidified and takes the oxygen from air. The FC system has a small intermediate battery for handling transient power changes, and thus enabling FC stack to deliver much greater life time. The battery prevents or limits the effects of gas starvation on the catalysts in a fuel cell by 'filtering' step changes in power demand into a smoother and more manageable power ramp, with the battery taking the bulk of the step change power demands. The fuel cell operates at low temperature $\left(60{ }^{\circ} \mathrm{C}\right)$, and atmospheric pressure. It is activated when the control system detects that the wind production is on an average less than $20 \mathrm{~kW}$ over 10 min. The FC system then powers the ground floor demand. Therefore, it works at partial load. The fuel cell specifications are summarised in the Table 5 . 


\section{Modelling of the Wind// $\mathrm{H}_{2}$ system}

This section covers the proposed methodology for modelling a Wind/ $\mathrm{H}_{2}$ system.

\subsection{Wind turbine model}

Wind turbine models can be categorised into detailed (or dynamic) models and simplified (or static) models. Detailed models [25,26] are useful to study the real turbine behaviour in the time frame of seconds while simplified models are more practical for the simulation of hours or days.

The wind turbine model utilised here is a static model; there-fore the inertia of the wind turbine is not taken into account. This assumption does not affect the results of the global model as the time constant of the wind turbine is in the order of seconds while the electrolyser thermal constant, for example, is in the order of minutes. In addition, it is not practical to include the complexity of a wind turbine dynamic model in a simulation that involves several multi-physic domain systems interconnected. Thus, the hypothesis of turbine static behaviour is a convenient approach for modelling a complete $\mathrm{Wind} / \mathrm{H}_{2}$ system.

Accordingly, the wind turbine has been modelled using the power curve given by the manufacturer. The Model input is a vector of the wind speed $(\mathrm{m} / \mathrm{s})$, each value sampled at interval of seconds, and the output is the wind turbine power (W). The wind data are fed into the Simulink environment in a matrix form, where the first column is the time vector and the second column is the wind speed. The wind data has been collected at the HO location in samples of $10 \mathrm{~min}$, and then expanded to seconds. A normally (Gaussian) distributed random signal is added to the wind data in order to emulate the wind speed variations in between samples [11].

\subsection{Alkaline electrolyser modelling}

The proposed model is based on steady-state electrochemical equations combined with thermal dynamic differential equations [21,22]. The model also takes into account the rectifier energy losses.

The proposed electrolyser model can be divided into three sub-models: the electrical, the thermal behaviour and the hydrogen production ones, all of them are strongly coupled and are non-linear. Fig. 3 shows the sub-models of the proposed electrolyser model.

The proposed modelling solver uses the electric power and the stack temperature as the electrical sub-model inputs, the stack voltage is then calculated by solving a non-linear system Eqs.(1) and (2). The Newton-Raphson (NR) method is an efficient way to do this, however when starting far from the solution, it may be expensive to compute. Another methodology, with less computational burden, has been used here. It is based on solving algebraic equations in Simulink by estimating the voltage at first iteration and using a block "memory" as feedback for consecutive iterations to break the algebraic loop. When a model contains an algebraic loop, Simulink uses the "Trust-region dogleg" method solver at each time step to solve the algebraic loop. A good starting point could be the system nominal voltage. The Simulink implementation of the proposed solving methodology is shown in Fig. 4.

The convergence of this iteration strategy has been found to be several orders of magnitude faster than using a traditional NR non-linear equation solver. Additionally, it has been found that the errors are not high if the study is in the time frame of seconds to hours (errors are only present in the time frame of milliseconds).

The output current and voltage signal values are then used as inputs to the "Hydrogen Production" sub-model (see Section 3.2.2) and the thermal sub-models (Section 3.2.3) respectively.

This model uses the input power to estimate the voltage-current relationship [9]. This relationship is given by:

$$
\begin{aligned}
& W=N I_{s t}^{e z} U_{\text {cell }} \\
& U_{\text {cell }}=U_{\text {rev }}+\frac{r}{A} I_{s t}^{e z}+s \log \left(\frac{t}{A} I_{s t}^{e z}+1\right)
\end{aligned}
$$

Where; $\mathrm{U}_{\text {cell }}$ is the electrolyser cell voltage, $\mathrm{r}$ is the parameter related to ohmic resistance of electrolyte $\left(\Omega \mathrm{m}^{2}\right), \mathrm{s}$ is the coefficient for overvoltage on electrodes $(\mathrm{V})$, and $\mathrm{t}$ is also a coefficient for overvoltage on electrodes but measured in (A $1 \mathrm{~m} 2$ ), A represents the electrolyser stack area. In Eq. (2), $\mathrm{W}_{-}$is the electrolyser power consumption in Watts, $\mathrm{N}$ is the stack cells, Istez is the stack current in amperes, and Urev is the reversible voltage dependant on the temperature and pressure of the reaction measured in volts. In thermodynamic terms Urev can be expressed as a function of the Gibbs energy: 


$$
U_{\text {rev }}=\frac{\Delta G}{z F}
$$

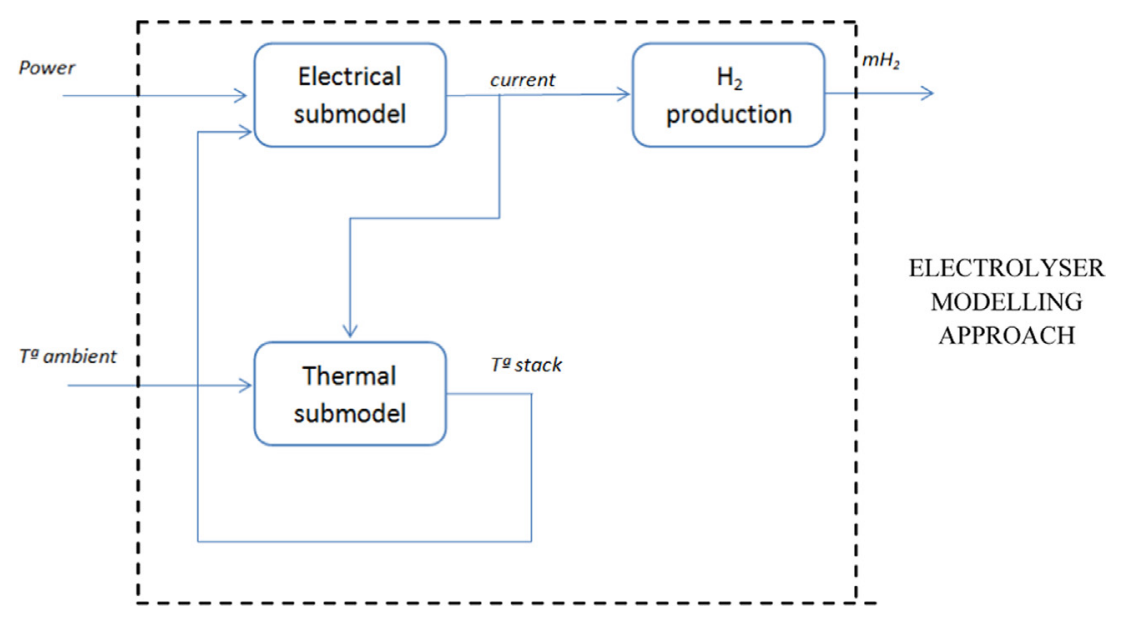

Fig. 3. Block diagram for building a dynamic model of an electrolyser. Power and ambient temperature are the model inputs and $\mathrm{H}_{2}$ mass flow is the main model output.

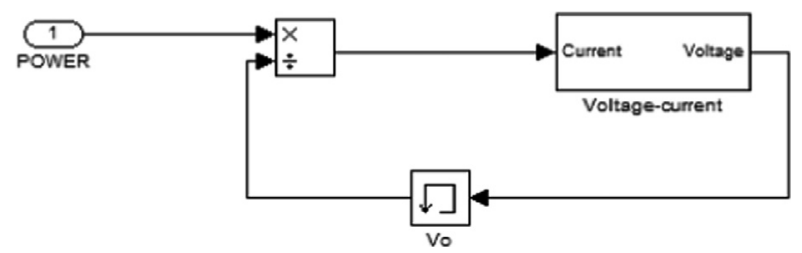

Fig. 4. Simulink model for solving the system electrical sub-model non-linear equations.

Where; $\Delta \mathrm{G}$ is the Gibbs free energy variation, $\mathrm{z}$ is the number of electrons and $\mathrm{F}$ is the Faraday constant.

The parameters involved in these calculations are: $r, s$ and $t$. These three parameters define the stack and the electrolyte type and the shape of the U-I curve. Parameters $r$ and $t$ also have a high dependence on the temperature (T) given by $\mathrm{r}(\mathrm{T})$ and $t(\mathrm{~T})$ :

$$
\begin{aligned}
& r(T)=r_{0}+r_{1} T \\
& t(T)=t_{0}+\frac{t_{1}}{T}+\frac{t_{2}}{T^{2}}
\end{aligned}
$$

\subsubsection{The hydrogen production sub-model}

The current through the stack determines directly the hydrogen production. Therefore, the stack current is modelled as input and the hydrogen production rate is the model output. The hydrogen flow rate ( $\mathrm{mol} \mathrm{s}^{-1}$ ) can then be calculated using Eq. (6):

$$
m_{H_{2}}=\eta_{F} \frac{N I}{Z F}
$$

where $z^{1 / 42}$ (number of electrons per hydrogen molecule), F $1 / 4$ Faraday constant $(96,500)$ and $\eta F$ is the Faraday efficiency, $N^{1 / 4}$ is the number of stack cells and I is the stack current (A). 
The Faraday efficiency is given by Eq. (7):

$$
\eta_{F}(\rho, T)=f_{2}(T) \frac{\rho^{2}}{\rho^{2}+f_{1}(T)}
$$

where: $f_{1}$ and $f_{2}$ are the empirical Faraday efficiency parameters taken from [21], $\rho$ is the current density $\left(A m^{-2}\right)$ and $T$ is the temperature $(\mathrm{K})$.

\subsubsection{The electrolyser thermal sub-model}

Heat is generated due to the irreversibility in the electrolysis process and must be removed in order to hold the nominal temperature. The thermal balance is completed when this waste heat is dissipated into the environment by, mainly, convection mechanisms [22]. The parameters involved in this heat transfer process are the thermal capacity $\left(\mathrm{C}_{\mathrm{t}}\right)$ and thermal resistance $\left(\mathrm{R}_{\mathrm{t}}\right)$. These parameters are estimated using experimental data.

The cooling system has been modelled here using the assumption that the system can remove all the generated waste heat when the maximum temperature is reached. In other words, when the temperature reaches its maximum value, the imple-mented control mechanism activates the fan. The fan is switched off when the temperature falls below a threshold. In practice, the fan generally removes more heat than what is generated. There-fore, the temperature drops towards a low threshold. At this point the fan is switched off. The electric consumption of the cooling system and the rest of BoP consumption is not taken into account in the model. Any parasitic consumption may be considered by pondering the final equipment performance.

The electrolyte temperature is a function of the input current and the RES power variation with time. Therefore, thermal inertia will play an important role in changing the operating point and the hydrogen production [21].

The electrolyte temperature is calculated by means of the energy balance:

$$
C t_{e z} \frac{d T_{e z}}{d t}=\dot{Q}_{g e n}-\dot{Q}_{\text {cool }}-\dot{Q}_{\text {loss }}
$$

where $\mathrm{T}_{\mathrm{ez}}$ is the electrolyser electrolyte temperature $(\mathrm{K}), \mathrm{Ct}_{\mathrm{ez}}$ is the electrolyser stack' thermal capacity (W/K), Qgen is the heat generated in the electrolysis process (W), Qcool is the cooling flux (W), Qloss is the heat losses (W).

The heat generated is associated to the thermodynamic irreversibility in the electrolysis process and it has been evaluated through Eq. (9)

$$
\dot{Q}_{g e n}^{e z}=N U_{s t}^{e z} I_{s t}^{e z}\left(1-\eta_{e}\right)
$$

where $\eta_{e}$ is the energy efficiency of the electrolysis process, $U$ is the stack voltage $(V), I$ is the stack current (A) and $N$ is the stack cells.

The heat loss term is quantified by the sum of convective and radiant losses to the environment. For simplicity, the heat loss has been expressed by (10):

$$
\dot{Q}_{\text {loss }}=\frac{1}{R_{t}}\left(T_{s t}^{e z}-T_{a}\right)+h_{f}^{e z}\left(T_{s t}^{e z}-T_{a}\right)+h_{n}^{e z}\left(T_{s t}^{e z}-T_{a}\right)
$$

where $R_{t}$ is the thermal resistance $(\mathrm{W} / \mathrm{K}), h_{f}^{e z}$ is the film coefficient for forced convection, $h_{n}^{e z}$ is the film coefficient for natural convection,

\begin{tabular}{|c|c|c|c|}
\hline Inputs & Parameters & & Outputs \\
\hline $\begin{array}{l}\text { Electrical power }(\mathrm{W}) \\
\text { Ambient temperature }(\mathrm{K})\end{array}$ & $\begin{array}{l}r_{0} \\
r_{1} \\
S \\
t_{0} \\
t_{1} \\
t 2 \\
f 1 \\
f 2 \\
C t_{e z} \\
R t_{e z} \\
A \\
h_{n}^{e z} \\
h_{c}^{e z}\end{array}$ & $\begin{array}{l}\text { Parameter related to ohmic resistance of electrolyte } \\
\text { Parameter related to ohmic resistance with temperature dependence on electrolyte } \\
\text { Coefficient for overvoltage on electrodes } \\
\text { Coefficient for overvoltage on electrodes } \\
\text { Coefficient for overvoltage on electrodes with temperature dependence on electrolyte } \\
\text { Coefficient for overvoltage on electrodes with temperature dependence on electrolyte } \\
\text { Parameter related to Faraday efficiency } \\
\text { Parameter related to Faraday efficiency } \\
\text { Overall thermal capacity of the electrolyser } \\
\text { Overall thermal resistance of the electrolyser } \\
\text { Area of the electrode } \\
\text { Natural heat transfer coefficient } \\
\text { Convective heat transfer coefficient }\end{array}$ & $\begin{array}{l}\mathrm{H}_{2} \text { production }\left(\mathrm{Nm}^{3} / \mathrm{h}\right) \\
\text { Stack voltage }(\mathrm{V}) \\
\text { Stack temperature }(\mathrm{K}) \\
\text { Stack current }(\mathrm{A})\end{array}$ \\
\hline
\end{tabular}
$T_{s t}^{e z}$ is the stack temperature (K) and $T_{a}$ is the environment temperature (assumed to $298 \mathrm{~K}$ ).

Table 6

Electrolyser model input signal, parameters and outputs. 
The cooling term becomes important when the upper tem-perature threshold is reached. The fan evacuates all the heat generated and slowly cools down the system. The hysteresis control strategy that has been implemented in the proposed model can be summarised as: when the temperature reaches $60{ }^{\circ} \mathrm{C}$ the fan is activated and when the temperatures falls below $57{ }^{\circ} \mathrm{C}$ the fan is switched off.

Table 6 gives a summary of the electrolyser model parameters, inputs and outputs.

\subsection{PEM fuel cell modelling}

This section describes the fuel cell model developed for the HO $10 \mathrm{~kW}$ Altergy PEMFC using a semi-empirical model adapted from Pukrushpan [28,29]. The developed model takes into account the energy losses associated with the inverter coupled to the fuel cell. The battery Simulink block, from the Simulink library, has been used to simulate the small lead-acid batteries linked to the FC to meet the fast transient loads. Describing a lead-acid battery model is out of the scope of this paper, which is focused on the hydrogen part.

Fuel cells (FC) are reliable energy sources that provide power using hydrogen. However, due to their slow mechanical ancillary and thermodynamics, fuel cells do not always offer fast demand response [30]. Therefore, it is necessary to have accurate dynamic models in order to study the fuel cell behaviour in different applications, such as hydrogen micro-grids. Such models allow FC system design and successful operation.

Among theoretical models, the one proposed by Pukrushpan [28] is well known and validated. This model describes with high accuracy the electrochemical process inside the fuel cell. The model takes into account parameters such as the dynamics of the compressor, the manifold filling dynamics and consequently the reactant partial pressures. On the other hand, empirical models [31], focus on fuel cell characterisation for specific operating conditions. The obvious drawback is the limited capacity for prediction outside their characterized operating conditions. However, these models are generally less computationally intense and easier to develop and use.

A key way of representing the FC behaviour is given by operational curve, better known as polarisation curve (which is the representation of the voltage versus current density). This voltage is a function of the reversible cell voltage, activation losses, ohmic losses and concentration losses [32]. Fluid dynamics inside the cathode and water flooding are neglected in the proposed model to make the simulation of the entire wind-hydrogen system feasible. Nevertheless, the model maintains high accuracy as it includes the cells dependency on temperature, membrane thickness, humidity and partial gas pressures.

The architecture of the model follows the same philosophy as the electrolyser model (Fig. 3). It has been broken down into sub-models to allow easy implementation in commercial Matlab-Simulink software. The voltage-current characteristic, the thermal model and the hydrogen consumption models are implemented in separate blocks connected to each other for variable exchange. The electrochemical equations (whose dynamics can be neglected) allow for the calculation of the stack voltage as function of: the current demanded, the temperature (time varying parameter), physical parameters such as membrane thickness, the humidity and the gas partial pressures (not time varying). The temperature is a feedback signal from the thermal block. The global variables for the fuel cell model are the load power demand $\left(\mathrm{P}_{\text {load }}\right)$ and the required output hydrogen flow rate $\left(\mathrm{n}_{\mathrm{fc}}\right)$.

Further to the aforementioned simplifications, the following common assumptions have been also used: one-dimensional treatment of flow and distribution gases; ideal and uniformly distributed gases; constant pressures in the fuel cell gas flow channels; the fuel is humidified pure hydrogen and the oxidant is humidified air; thermodynamic properties are evaluated at aver-age stack temperature; temperature variations across the stack are neglected; stack heat capacity is constant [28].

\subsubsection{The fuel cell electrical sub-model}

The system equations used to describe the electrical behaviour of a single cell are drawn from [28]:

$$
\begin{aligned}
& V_{\text {cell }}=E-V_{\text {act }}-V_{\text {ohm }}-V_{\text {conc }} \\
& E=1.229-8.5 \cdot 10^{-4}\left(T_{s t}^{f c}-298.15\right)+4.308 \cdot 10^{-5} T_{s t}^{f c}\left[\ln P_{\mathrm{H}_{2}}+0.5 \ln P_{\mathrm{O}_{2}}\right]
\end{aligned}
$$

$$
\begin{aligned}
V_{a c t} & =x_{1}-8.5 \cdot 10^{-4}\left(T_{s t}^{f c}-298.15\right)+4.308 \cdot 10^{-5} T_{s t}\left[\ln P_{\mathrm{H} 2}+0.5 \ln P_{O_{2}}\right]+ \\
& +\left[\left(x_{2} T_{s t}^{f c}+x_{3}\right) P_{O_{2}}^{2}+\left(x_{4} T_{s t}^{f c}+x_{5}\right) P_{O_{2}}+\left(x_{6} T_{s t}^{f c}+x_{7}\right)\right] \cdot\left(1-e^{-x_{8} I_{s t}^{f c}}\right)
\end{aligned}
$$

$$
V_{\text {ohm }}=\frac{I_{s t}^{f c} \cdot t_{m}}{\left(0.005139 \lambda_{m}-0.00326\right) e^{\chi_{9}\left(\frac{1}{303}-\frac{1}{T_{s t}^{c c}}\right)}},
$$

$$
V_{\text {conc }}=I_{s t}^{f c}\left[\left(x_{10} T_{s t}^{f c}+x_{11} P_{O_{2}}\right) \frac{I_{s t}^{f c}}{x_{12}}\right]^{x_{13}} \text {. }
$$


where $\mathrm{V}_{\text {cell }}$ is the cell voltage $(\mathrm{V}), \mathrm{I}_{\mathrm{st}}^{\mathrm{fc}}$ is the stack current $(\mathrm{A}), \mathrm{T}_{\mathrm{st}}^{\mathrm{fc}}$ is the stack temperature $(\mathrm{K}), \mathrm{PO} 2$ is the oxygen partial pressure (bar), $\mathrm{P}_{\mathrm{H} 2}$ is the hydrogen partial pressure (bar), $\mathrm{t}_{\mathrm{m}}$ is the membrane thickness $(\mathrm{mm}), \lambda_{\mathrm{m}}$ is the stack humidity, which varies between $0(0 \%$ humidity) and 14 (100\% humidity). As it is known, the complete stack power is given by simply $\mathrm{P}_{\mathrm{fc}} \frac{1 / 4}{4} \mathrm{n}_{\text {cells }} \cdot \mathrm{V}_{\text {cell }} \cdot \mathrm{I}$ fc ${ }_{\text {st }}$, with $\mathrm{n}_{\mathrm{ce}}$ the total number of cells of the stack.

The coefficients $\mathrm{x}_{1}-\mathrm{x}_{13}$, are the values that create the best fit between the model and the gathered data. This model enables the prediction of the fuel cell behaviour for different operational conditions, since the equations take into account the stack temperature, gases partial pressures and stack currents, which makes it favourable when compared with fully empirical models.

\subsubsection{The hydrogen consumption sub-model}

The hydrogen required for the fuel cell to produce the power demanded is calculated through the stoichiometric equation:

$$
\dot{m}_{f c}=\frac{n_{\text {cells }} I_{s t}^{e z}}{z \cdot F}
$$

where $\underline{m} \mathrm{fc}$ is the flow of hydrogen required $(\mathrm{mol} / \mathrm{s}), \mathrm{n}_{\mathrm{cells}}$ is the number of cells in the fuel cell, $\mathrm{I}_{\mathrm{st}}^{\mathrm{ez}}$ is the current delivered by the fuel cell stack (A), $\mathrm{z}$ is the number of electrons per molecule (2), $\mathrm{F}$ is the Faraday constant $(96,500)$.

\subsubsection{The fuel cell thermal sub-model}

As with the electrolyser, the FC thermal model to determine the stack temperature $(\mathrm{Tc} s t)$ is implemented as a lumped thermal capacitance model. The heat generated during the fuel cell operation is due to entropy changes. Thus, the first law of thermodynamics is expressed as:

$$
C_{t}^{f c} \frac{d T_{s t}^{f c}}{d t}=\dot{Q}_{H_{\text {reac }}}-W_{\text {elec }}-\dot{Q}_{a}
$$

The first term on the right hand of the equation describes the enthalpy of the chemical reaction of water formation. The second term is the energy yielded in the form of electricity generation. The third term refers to the amount of heat dissipated through convection effects to the environment, which includes the heat removed by the cooling system when the fuel cell reaches the maximum temperature allowed. The fuel cell cooling runs proportionally to power production. When the nominal temperature $\left(60^{\circ} \mathrm{C}\right)$ is reached the fan is full powered to cool the stack and keep it at the nominal temperature.

The different terms of the energy balance can be calculated as:

$$
\begin{aligned}
& \dot{Q}_{H_{\text {reac }}}=\frac{-\Delta H_{\text {reac }} \cdot I_{f c}}{2 F} \\
& W_{\text {elec }}=V_{f c} I_{f c} \\
& \dot{Q}_{a}=\left(h_{c}^{f c}+h_{n}^{f c}\right) \cdot\left(T_{s t}^{f c}-T_{a}\right)
\end{aligned}
$$

where $\Delta \mathrm{H}_{\text {reac }}$ is the enthalpy of the reaction, $\mathrm{F}$ is the Faraday constant, $\mathrm{I}_{\mathrm{fc}}$ is the stack current, $V_{\mathrm{fc}}$ is the stack voltage, $\mathrm{h}_{\mathrm{c}}^{\mathrm{fc}}$ and $\mathrm{h}_{\mathrm{n}}^{\mathrm{fc}}$ are the convective and natural heat transfer coefficients of the fuel cell, $\mathrm{T}$ st is the stack temperature and $\mathrm{T}_{\mathrm{a}}$ is the environmental temperature $(298 \mathrm{~K})$.

The model parameters, the input, and the outputs for the fuel cell type used in this study are presented in Table 7.

Table 7

Single stack PEM FC model parameters.

\begin{tabular}{llll}
\hline Inputs & Parameters & Outputs \\
\hline $\begin{array}{c}\text { Electrical power } \\
(\mathrm{W})\end{array}$ & $X_{1}-X_{13}$ & $\begin{array}{l}\text { Polarisation curve fit- } \\
\text { ting parameters } \\
\begin{array}{c}\text { Ambient tempera- } \\
\text { ture (K) }\end{array}\end{array}$ & $\begin{array}{l}\mathrm{H}_{2} \text { consumption } \\
\left(\mathrm{Nm}^{3} \mathrm{~h}^{-1}\right)\end{array}$ \\
& & $\begin{array}{l}\text { Convective heat trans- } \\
\text { fer coefficient } \\
\text { Stack voltage (V) }\end{array}$ & \\
& $h_{n}^{f c}$ & $\begin{array}{l}\text { Natural heat transfer } \\
\text { coefficient } \\
\left(\mathrm{W} \mathrm{m}^{-2} \mathrm{~K}^{-1}\right)\end{array}$ & $\begin{array}{l}\text { Stack temperature } \\
\text { (K) })\end{array}$ \\
& & Thermal Capacity \\
& $C_{t}^{f c}$ & Stack current (A) & \\
\hline
\end{tabular}




\subsection{Storage system modelling}

The hydrogen storage tank level has been modelled here using mass balance. The stored hydrogen rate depends on three terms: the hydrogen production from the electrolyser $\left(\dot{\mathrm{m}}_{\mathrm{ez}}\right)$, the hydrogen flow required from the fuel cell $\left(\mathrm{m}_{\mathrm{fc}}\right)$ and finally leakage rate to the environment $\left(\mathrm{m}_{\text {leak }}\right)$.

$$
m_{t k}=m_{e z}-m_{f c}-m_{l e a k}
$$

The control variable considered here is the tank level. Neglecting the leakage term, since it is small compared to usage, the amount of hydrogen in the tank is given by:

$$
m_{t k}=m_{0} \int \dot{m}_{e z}-\dot{m}_{f c} d t
$$

The second control variable is the tank pressure. Taking into account that pressure and temperature of the hydrogen inside the tank is low, we can assume ideal gas conditions. Therefore, the tank pressure is easily obtained from:

$$
p_{t k}=n_{t k} R T_{t k} / V l_{t k}
$$

where $n_{t k}$ is the moles of hydrogen into the tank. $\mathrm{R}$ is the ideal gas constant. $\mathrm{T}_{\mathrm{tk}}$ is the temperature of the hydrogen in the tank and $\mathrm{Vl}_{\mathrm{tk}}$ is the volume of the tank.

\section{Case study: The Hydrogen Office (HO) system model and parameters}

\subsection{Parameter estimation and validation methodology}

With many of the equations describing the Wind/ $\mathrm{H}_{2}$ equipment being empirical, it is necessary to estimate a considerable number of parameters. Thus, achieving accurate parameter estimation becomes a key point in modelling tasks. Different issues were found in the process of obtaining the parameters. For example, the main parameters for tailoring any alkaline electrolyser model are: $r$, $\mathrm{s}, \mathrm{t}, \mathrm{f}_{1}, \mathrm{f}_{2}, \mathrm{R}_{\mathrm{t}}, \mathrm{C}_{\mathrm{t}}$ and $\mathrm{A}$. And there are essentially two ways to obtain these parameters:

1. Performing specific experimental test in order to find out the electrolyser parameters.

2. Based on manufacturer's datasheet or literature.

Although the first method is the best way to find model parameters, specific experimental tests might not be possible to be performed in practice, such as in our case-study, the $\mathrm{HO}$, due to it is a system that is already installed and operating and therefore it will consequently be 'closed' for testing individual components. Some of the parameters might be found in the available literature. However, literature typically focuses on educational-oriented equipment while in real world plants, commercial equipment are used and therefore, many important parameters needed for modelling are part of the know-how of manufacturers, who not usually disclose this kind of information in the brochures. Another parameter estimation guideline is to reduce first the number of modelling parameters as much as possible while attempting to not lose accuracy in the results. In order to address the aforemen-tioned issues and identify the parameters for the fuel cell and the electrolyser, we applied a parameter identification methodology based on the logical approach presented in Fig. 5 .

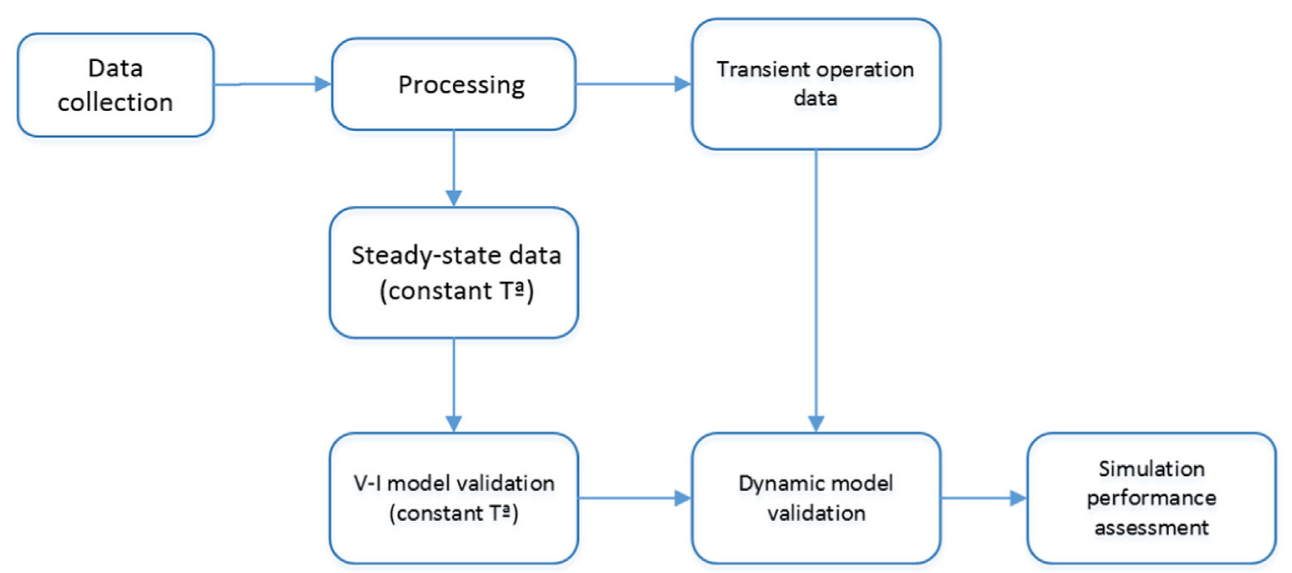

Fig. 5. Parameter estimation methodology and validation procedure [22]. 
According to the modelling methodology proposed in Section 3, which separates the electrical (static) and thermal (dynamic) characteristics of the electrolyser/fuel cell, it is necessary a separated parameter estimation process for each part.

In the first stage of this approach, experimental data from the plant operation are collected. This data contains the full range of operating power and possible temperatures (start-up, shut downs, steady power, transients, etc.). Then, it is necessary to classify the data. Therefore, sets of input-output values are grouped with respect to constant values of temperature. In contrast, transient operation data, for the dynamic model validation, should be selected stepping their power input value (the power derived to the electrolyser or the fuel cell) for example start-up and shut-down process in order to get a set of voltage, current and stack temperature values which clearly varies with time.

The following stage is then to find out the parameters for the voltage-current curve, which rely only on the stack type. The thermal model which depends on external conditions, such as the ambient temperature, can be fitted later.

Finally, we can compare the modelled system response to the real system behaviour in order to validate the models.

Both the U-I model validation and the dynamic model validation will then require the use of the parameter optimisation tools.

The following guidelines are concluded to be taken into consideration when modelling operational performance:

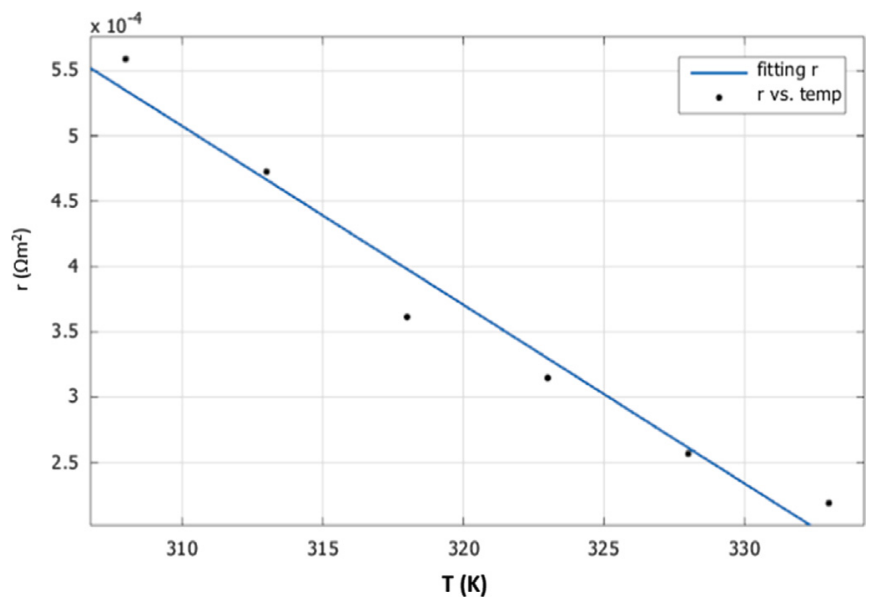

Fig. 6. Linear parameter " $r$ " fitting using experimental data of U-I curve at each temperature. Each value of $r$ obtained from fitting U-I curve of the model with experimental data is represented as function of temperature (in kelvin) at abscissa axis.

- Collect a consistent set of plant operational data that sweeps all the operating conditions.

- Process the data in order to obtain:

1. Steady-state operation data: by selecting the data with same (or approximately same) temperature values.

2. Transient operation data: by selecting the data representing a typical step in the input or transient behaviour (different temperature conditions).

- Validate the static behaviour using the previously processed data to find out the parameters with no dependence on the dynamics. Voltage-current curves.

- Validation of the dynamic behaviour using the step and transient profile data in conjunction with the optimisation tool to identify the model dynamic parameters.

- Develop a simulation model for each component in the system, perform simulations and compare results versus the real operational data to assess each model accuracy before the integration of sub-models. 


\subsection{Alkaline electrolyser parameter estimation and model validation}

For the electrolyser, the parameters $\mathrm{r}, \mathrm{s}$ and $\mathrm{t}$ have to be iden-tified at the steady-state validation stage (Section 4.2.1), while the thermal parameters $\left(\mathrm{h}_{\mathrm{c}}, \mathrm{h}_{\mathrm{n}}, \mathrm{C}_{\mathrm{t}}, \mathrm{R}_{\mathrm{t}}\right)$ are identified at the dynamic validation stage (Section 4.2.2).

\subsubsection{Electrolyser steady-state parameter identification}

By implementing the procedure described in Fig. 5, the para-meter " $r$ " was identified using standard Matlab curve fitting tool while holding the rest of the voltage-current parameters ( $\mathrm{s}$ and $\mathrm{t}$ ) at their initial values. Each value of $\mathrm{r}$, with $\mathrm{r}^{1 / 4} \mathrm{hropr} 1 \cdot \mathrm{T}$, in Fig. 6 was determined by fitting Eq. (2) at each temperature with the experimental data processed. Curve fitting tool enables visual data

exploration and scatter plots fitting. This process is repeated for each value of temperature. Fig. 6 shows the dependence found for the parameter " $r$ " with temperature, on using this tool.

Similarly, the parameter " $\mathrm{t}$ " was identified for different temperatures, by keeping the " $\mathrm{r}$ " parameter constant and using the fitting tool. We found that the dependence of parameter "t" on temperature, that Fig. 7 shows, is different from that suggested in previous works such as [22], but in concordance with more recent developments, such as [21].

According to Fig. 7 results, the dispersion of points recom-mends to substitute Eq. (5) for the expression obtained in the fitting process:

$$
t(T)=t_{0}+t_{1} T+t_{2} T^{2}
$$

The parameter " $s$ " has been chosen to be 0.35 , as in Refs.[21,22,27], resulting in a good agreement with the experimental data. Given this agreement, no further optimisation was necessary. In general the process to determine this parameter would consist of a search of the same electrolyser's electrode technology and look for the overvoltage potential.

The electrode area is an unknown parameter that cannot be calculated without the voltage-current density curve, which is not available for our case study. This issue has been overcome by considering that the electrical characteristic (voltage-current curve) can be determined by first estimating the electrode area and calculating the coefficients $r, s$ and $t$ for this estimated area, then adjusting $\mathrm{r}$ and $\mathrm{t}$ so that any possible disparity in the initial electrode area choice is balanced. This is entirely valid since the electrode area is a design parameter that does not need to be modified in performance simulations as opposed to operating parameters, such as temperature and pressure that should be accessible in the model in order to allow simulations under different operation conditions.

To calculate the coefficient $\mathrm{fl}$ for the HO electrolyser from faraday efficiency (Eq. (7)), a linear dependence with the tem-perature was assumed. On the other hand, for the coefficient $\mathrm{f} 2$ a quadratic dependence is more appropriate based on the experi-mental data of [22] for Hysolar and Phoebus coefficients.

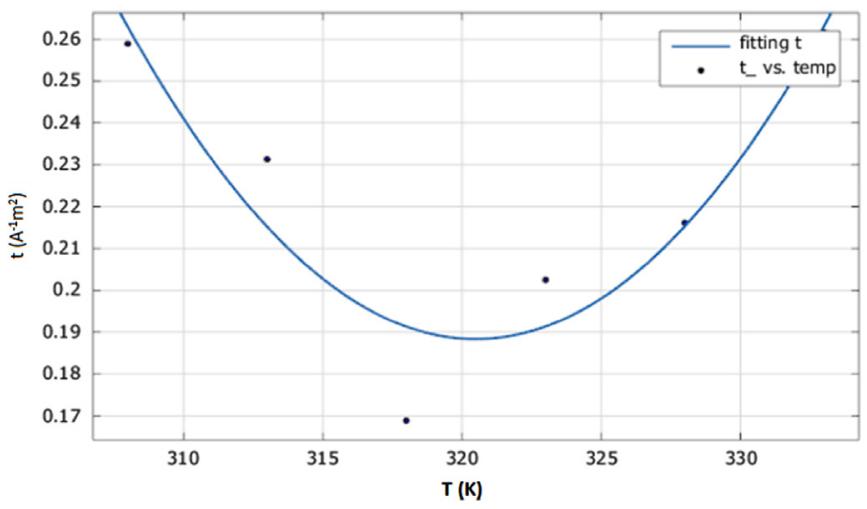

Fig. 7. Parameter $t$ fitting using experimental data of U-I curve at each tempera-ture. Each value of $t$ obtained from fitting U-I curve of the model with experimental data is represented as function of temperature (in kelvin) at abscissa axis. 


\subsubsection{Electrolyser dynamic parameters identification}

In this section, the parameters $\mathrm{C}_{\mathrm{t}}, \mathrm{h}_{\mathrm{c}}, \mathrm{h}_{\mathrm{n}}$, and $\mathrm{R}_{\mathrm{t}}$ are going to be identified. An optimisation technique is implemented to find out these parameters. The Matlab-Simulink block: "Signal Constraint" is the tool used for the dynamic parameters optimisation. This optimisation minimises the error between the model present output signal (stack temperature) and the reference signal (experimental temperature data) sweeping different operation levels. All the "static" parameters that has been obtained in the previous section are kept fixed once optimised, while the "dynamic" heat transfer coefficients depend on the site conditions so are therefore optimised based on the HO environmental con-ditions. A multi-parameter optimisation technique is implemented in the "Signal Constraint" tool. It is advisable to reduce the complexity of the optimisation as much as possible. In this case, two parameters $\left(\mathrm{C}_{\mathrm{t}}\right.$ and $\left.\mathrm{R}_{\mathrm{t}}\right)$ were identified by running the optimisation separately. The "Signal Constraint" tool also allows adjusting the natural and force convection parameters $\left(h_{c}\right.$ and $\left.h_{n}\right)$, which are also uncertain. By using this methodology, parameters can be tuned for any electrolyser design and operating conditions.

Table 8 gives a summary of results obtained from Sections 4.2.1 and 4.2.2, where the parameters are estimated using the afore-mentioned optimisation technique for our case study, the HO.

Table 8 parameter values have been found to be reasonable by comparing them with those of similar electrolysers $[33,21,22]$. Note that, during the optimisation process boundaries had been set for the parameters in order to avoid values that are non-physical.

\subsubsection{Electrolyser model validation results}

According to the methodology proposed in Section 4, the I-U curves obtained from the developed model (by means of current sweeps at different temperatures) are validated using experi-mental data. Only the steady-state data must be used in this step of the validation process in order to clearly identify the voltage-current characteristic. The steady-state data are grouped around 60 A current and 2-2.5 cell stack volts, which corresponds with electrolyser nominal operating conditions. The variations on the electrolyte temperature are reflected in the different potentials (curves) that can be seen in Fig. 8. The group of data gathered under the title "unused data" are related to the transient state while the electrolyser is reaching nominal temperature conditions and therefore are data that must be ignored at this stage, although they will be used at the dynamic validation stage.

Table 8

Alkaline electrolyser model parameters.

\begin{tabular}{|c|c|c|c|}
\hline Parameter & Description & Value & Units \\
\hline$r_{0}$ & Parameter related to ohmic resistance of electrolyte & 0.004747 & $\mathrm{VA}^{-1} \mathrm{~m}^{2}$ \\
\hline$r_{1}$ & Parameter related to ohmic resistance with temperature dependence on electrolyte & $-1.367 \cdot 10^{-5}$ & $\mathrm{VA} \mathrm{A}^{-1} \mathrm{~m}^{2}{ }^{\circ} \mathrm{C}^{-1}$ \\
\hline$s$ & Coefficient for overvoltage on electrodes & 0.35 & $\mathrm{~V}$ \\
\hline$t_{0}$ & Coefficient for overvoltage on electrodes & 49.31 & $\mathrm{~A}^{-1} \mathrm{~m}^{2}$ \\
\hline$t_{1}$ & Coefficient for overvoltage on electrodes with temperature dependence on electrolyte & -0.3065 & $\mathrm{~A}^{-1} \mathrm{~m}^{2}{ }^{\circ} \mathrm{C}$ \\
\hline$t_{2}$ & Coefficient for overvoltage on electrodes with temperature dependence on electrolyte & 0.0004782 & $\mathrm{~A}^{-1} \mathrm{~m}^{2}{ }^{\circ} \mathrm{C}^{2}$ \\
\hline$f_{1}$ & Parameter related to Faraday efficiency & 20,000 & $\mathrm{~A}^{2} \mathrm{~m}^{-4}$ \\
\hline$f_{2}$ & Parameter related to Faraday efficiency & 0.93 & - \\
\hline$C t_{e z}$ & Overall thermal capacity of the electrolyser & $1.6824 \cdot 10^{5}$ & $\mathrm{JK}^{-1}$ \\
\hline$R t_{e z}$ & Overall thermal resistance of the electrolyser & 0.4441 & $\mathrm{~W} \mathrm{~K}^{-1}$ \\
\hline$A$ & Area of the electrode & 0.06 & $\mathrm{~m}^{2}$ \\
\hline$h_{n}^{e z}$ & Natural heat transfer coefficient & 6 & $\mathrm{~W} \mathrm{~K}^{-1}$ \\
\hline$h_{c}^{e z}$ & Convective heat transfer coefficient & 30 & $\mathrm{~W} \mathrm{~K}^{-1}$ \\
\hline
\end{tabular}

Once the static behaviour has been successfully validated, the dynamic validation process consists in performing a test where the power consumed by the electrolyser varies with time and consequently the temperature, voltage and current varies. Within the experimental data from the plant operation, a typical step event has been selected for the validation.

During the dynamic test, the overall thermal capacity $\mathrm{Ct}$ and the thermal resistance $\mathrm{Rt}$ are the parameters to be determined by the optimisation process. The electrolyser stack voltage, current and temperature experimental data under transient load conditions are compared versus the model outputs as shown in Fig. 9.

Fig. 9(a) shows the power input to the electrolyser used for the dynamic validation procedure. The electrolyser power consumption is increased drastically from zero to around $25 \mathrm{~kW}$. Then, the electrolyser is operated around rated power during 10 min approximately. In Fig. 9(c) it can be observed how the stack vol-tage gradually drops as consequence of the temperature rising. Validation results show a very good fit to the gathered onsite data, with only $1 \%$ error in U-I curve and $2.4 \%$ in stack temperature. The figures demonstrate the accuracy of the model in predicting the dynamic behaviour of the electrolyser, such as voltage and current variations (shown in Fig. 9(a)) and (b)), according to temperature and power changes.

\subsection{Fuel cell parameter estimation and validation}

The fuel cell parameter estimation methodology follows the same principle discussed in Section 4.1. Voltage-current para-meters (the coefficients $\mathrm{x} 1-$ $\mathrm{x} 13$ ) are determined using steady-state data while dynamic parameters are estimated through transient data once the static behaviour has been validated. 
4.3.1. Fuel cell steady-state parameter identification

The steady-state parameter identification process consists in collecting the voltage-current (V-I) values for the entire operational range of the fuel cell. The lack of data points through the whole FC temperature range has led to grouping the values gathered around a range of $35-55^{\circ} \mathrm{C}$. The curve fitting tool needs at least 13 data points to determine the 13 coefficients $\mathrm{x} 1-\mathrm{x} 13$.

The I-V curve has been fitted using a single cell voltage and stack current values. The parameter values for the active cell area and the membrane thickness have been taken from literature [34].

Fig. 10 shows the results of the steady-state validation for the fuel cell polarisation curve. The trust-region optimisation search method has been used to minimise the objective function for fitting the collected data and the model prediction output. As can be seen in Fig. 10, the model is able to predict the activation and ohmic zones. The concentration zone is not represented because the data needed for this zone are out of the fuel cell operating range.

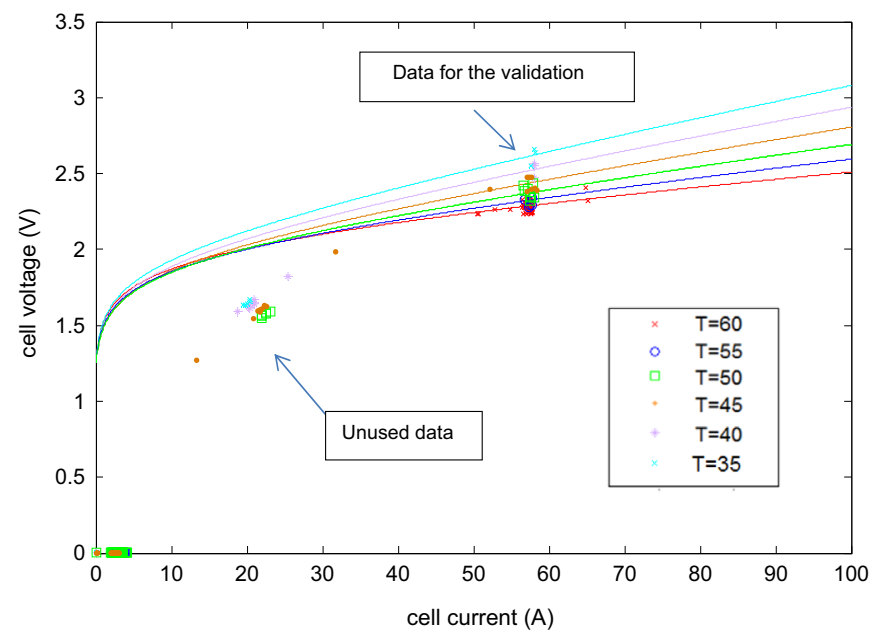

Fig. 8. I-U curve validation at different temperatures. The $\mathrm{I}-\mathrm{U}$ is for each cell of the stack. Dots show experimental points gathered. Continuous lines represent model prediction.
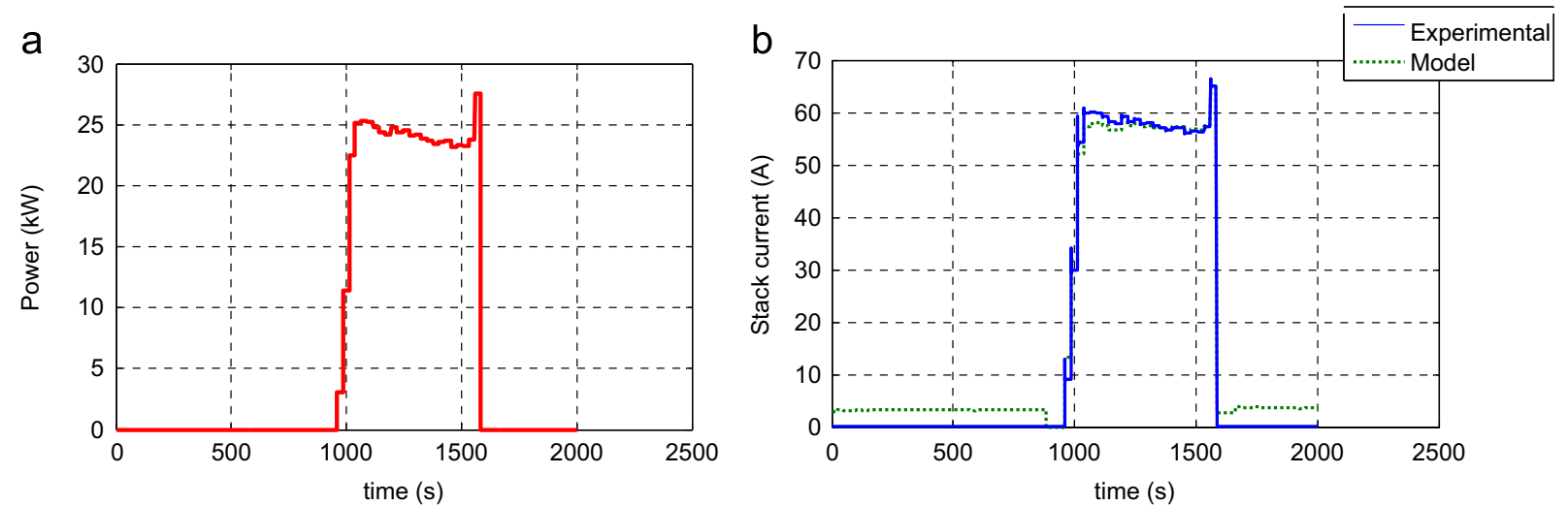

C

d
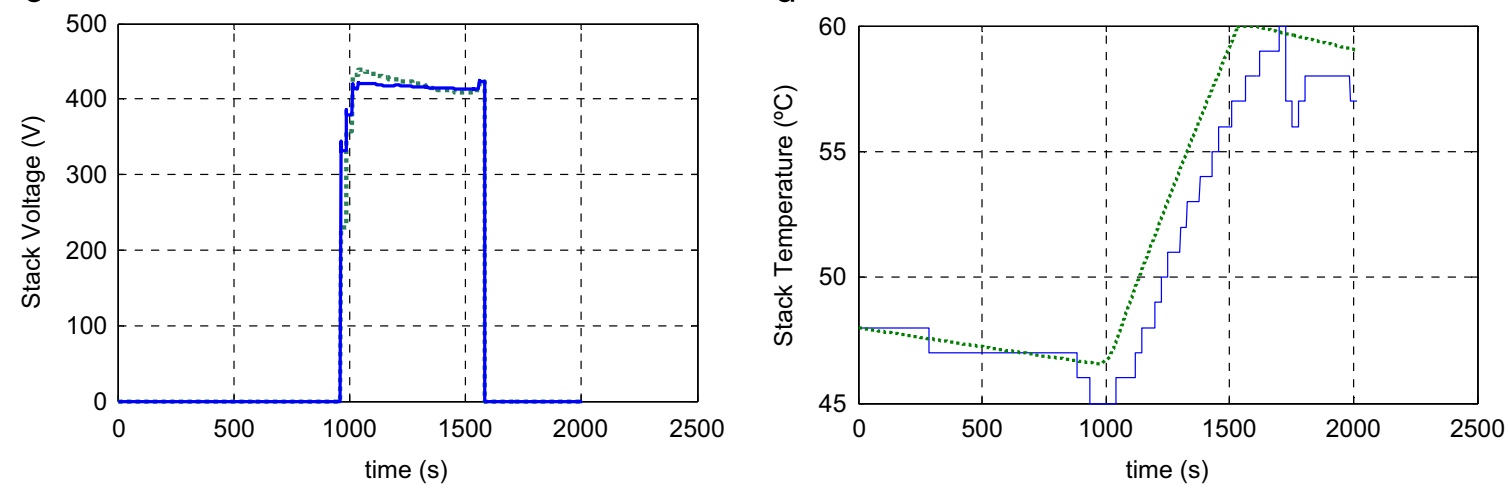

Fig. 9. Validation of the electrolyser model in dynamic test. Fig. 9(a) shows the model input used for validation. The prediction of the model versus experimental data gathered are shown at Fig. 9(b) Stack current, (c) stack voltage and (d) stack temperature. 


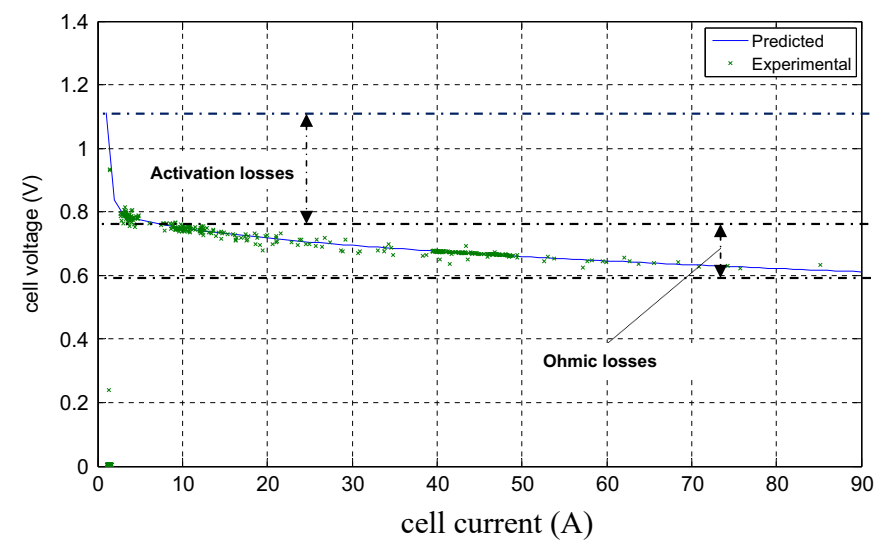

Fig. 10. I-U curve validation at different temperatures. The $\mathrm{I}-\mathrm{U}$ is for each cell of the stack. Dots show experimental points gathered. Continuous lines represent model prediction.

\subsubsection{Fuel Cell dynamic parameters identification}

The aim of this section is to find out the stack heat capacity $\mathrm{C}_{\mathrm{t}}^{\mathrm{fc}}$, which will allow the model to accurately reflect the temperature changes in the fuel cell. The ambient temperature dependant coefficient $\left(\mathrm{h}_{\mathrm{n}}^{\mathrm{fc}}\right)$ and the cooling system coefficient $\left(\mathrm{h}_{\mathrm{c}}^{\mathrm{fc}}\right)$ are also to be tuned.

The dynamic parameters optimisation method used here follows the same approach carried out for the electrolyser parameter estimation. The results of dynamic behaviour are presented throughout Fig. 11 with clear transient data of the fuel cell operation.

Fig. 11(a) shows the model input with FC operational data available ranges from $500 \mathrm{~W}$ up to $2900 \mathrm{~W}$ for a period of $24 \mathrm{~h}$. This profile has been chosen because of its high variability in the power shape in order to demonstrate the accuracy of the dynamic model. It is important to notice the model prediction in relation to the voltage, Fig. 11(c), and current Fig. 11(b), in different operating conditions has an error lower than $0.2 \%$. The evolution of FC stack temperature is explained in the power changes of the experiment. Although the fuel cell never reaches a particular operating point, the model shows a good fitting of stack temperature (Fig. 11(d)) with a maximum error of $4 \%$.

\subsubsection{Fuel cell parameters}

The final parameters obtained for the fuel cell model are shown in Tables 9 and 10. The polarisation curve parameters $\mathrm{X}_{1}-\mathrm{X}_{13}$ shown in Table 9, describe the best fit to replicate the PEMFC polarisation curve. The thermal dynamic coefficients of the fuel cell are summarised in Table 10.

Table 9

Fuel cell coefficients for the I-V curve.

\begin{tabular}{lllllllllllll}
\hline$X_{1}$ & $X_{2}$ & $X_{3}$ & $X_{4}$ & $X_{5}$ & $X_{6}$ & $X_{7}$ & $X_{8}$ & $X_{9}$ & $X_{10}$ & $X_{11}$ & $X_{12}$ & $X_{13}$ \\
\hline 23.06 & 4.236 & -7.808 & 6.413 & 0.3629 & -1.873 & 112.3 & 2.073 & $-2.283 \cdot 10^{4}$ & 15.67 & -127.9 & 33.62 & -0.6211 \\
\hline
\end{tabular}

Table 10

Thermal coefficients of the PEM FC.

\begin{tabular}{lll}
\hline Parameter & Description & Value \\
\hline$C_{t}^{f c}$ & Thermal capacity & $11,005 \mathrm{~J} \mathrm{~K}^{-1}$ \\
$h_{n}^{f c}$ & Natural convection coefficient & $6 \mathrm{~W} \mathrm{~m}^{-2} \mathrm{~K}^{-1}$ \\
$h_{c}^{f c}$ & Forced convection coefficient & $20 \mathrm{~W} \mathrm{~m}^{-2} \mathrm{~K}^{-1}$ \\
\hline
\end{tabular}



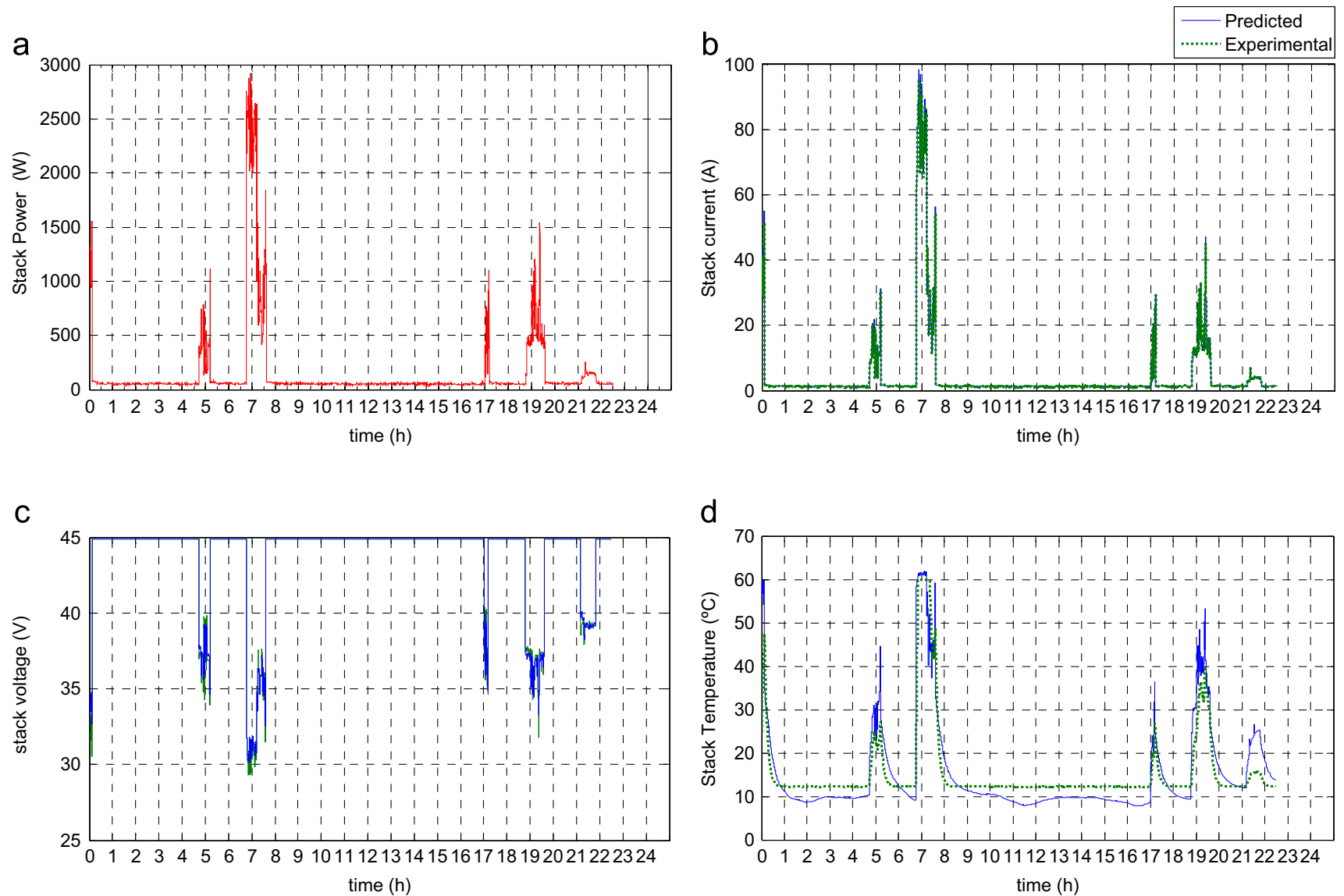

Fig. 11. Validation of the fuel cell model in dynamic test. Fig. 11(a) shows the model input used for validation, and the prediction of the model versus experimental data gathered are shown at Fig. 11(b) stack current, (c) stack voltage and (d) stack temperature.

\section{Simulation of the integrated system}

This section describes how the models have been integrated to perform a global system simulation. The previously discussed individual models have been combined, exchanging the state variables through the integrated structure shown in Fig. 12.

To complete the calculations of the integrated system without incurring in algebraic loops, variable initial values must be set into the "Integration block" of each subsystem.

The overall system model is completed by the Master Control subsystem. This block receives the state variable(s) as inputs and computes the control signals as outputs. The control signals are the power references for the electrolyser, the fuel cell and the electricity exported/imported from the grid. The state variable in this case is the storage level.

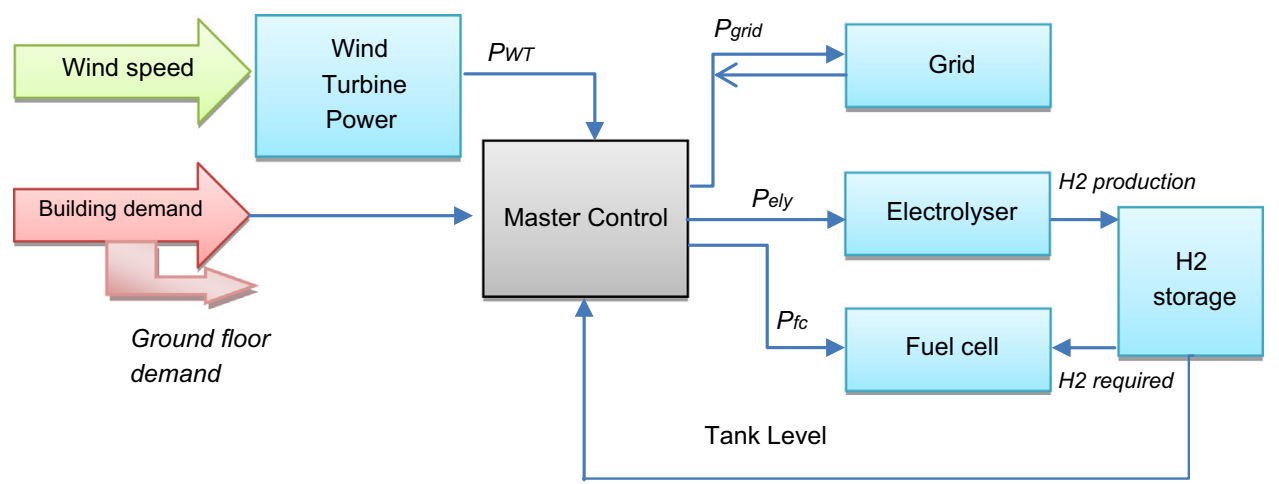

Fig. 12. Flow scheme for the Simulink implementation of the Hydrogen Office model. Overall inputs are the wind speed and the building demand. 


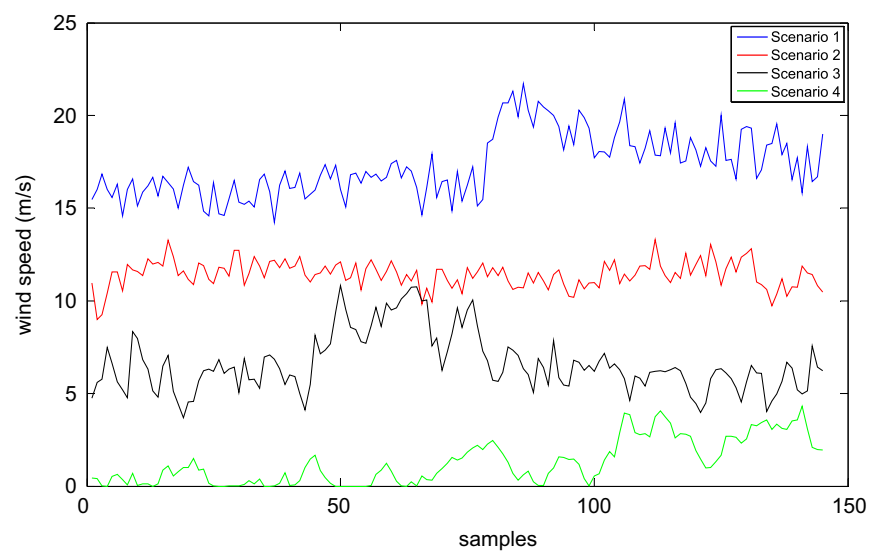

Fig. 13. Wind speed profiles in the representative scenarios for simulation assessment.

Once the integrated model has been completed, its performance has been assessed by means of representative simulations. Four scenarios has been selected for the assessment in order to demonstrate the FC and the electrolyser operation in different weather conditions.

Sections 5.1 and 5.2 outline the simulations performed under different wind conditions. The wind velocity data that has been gathered onsite for a random month were processed to select four types of representative scenarios as it is shown in Fig. 13. Scenario 1 represents the case of extremely favourable wind conditions, while Scenario 4 represents the opposite case of extremely scarce wind velocity. Two intermediate scenarios, Scenario 2 and Scenario 3, were chosen between those extreme cases. The expected operation schedule is a stable electrolyser operation in "Scenario 1" and "Scenario 2". In contrast, in Scenario 3, it is expected an intermittent electrolyser operation. It is not probable to activate the fuel cell between "Scenarios 1"-“3", while in "Scenario 4", the fuel cell operation should be predominant.

\subsection{Scenario 1 and Scenario 2: Strong wind and electrolyser operation}

In order to illustrate the performance of the system in high wind scenarios, Scenarios 1 and 2 simulation results are described in this section. The wind data have been gathered at Methil (Scotland), in 10 min intervals (as usual in data acquisition systems). Each simulation took $4 \mathrm{~min}$ and $22 \mathrm{~s}$ with a $3.3 \mathrm{GHz} \times 8$ microprocessors (8 GB RAM) computer.

Simulation results are shown in Fig. 14, where it can be observed that the power produced by the WT resulted in a high and stable output. Fig. 14(a) shows Scenario 1, in which the turbine is working around its maximum capacity. The WT power production is almost constant due to the turbine working in the flat zone of its power curve. As it was expected, this stable power keeps the electrolyser working at its nominal conditions during the whole day, producing hydrogen until the tank is filled. The power balance is guaranteed by the grid exported power. Therefore, the electricity that is exported to the grid corresponds to the power that the electrolyser cannot use. The electrolyser control system works as follows: when the control system detects an average power from the WT above $80 \mathrm{~kW}$, for $10 \mathrm{~min}$, a command is sent to activate the electrolyser. In contrast, when turbine average power production is below the electrolyser minimum threshold ( $70 \mathrm{~kW}$ average power over $10 \mathrm{~min})$, the electrolyser is switched off. The electrolyser is also switched off when the $\mathrm{H} 2$ tank is full. It can be deducted from Fig. 15 that the electrolyser is not switched off because of low WT power, but because the tank is filled.

The electrolyser operation for the HO system (our case study) at full power in both scenarios can be explained as follows: The start-up process ramps the power to the electrolyser over the course of two minutes until it reaches the rated power ( $30 \mathrm{~kW})$. As it can be observed in Fig. 15, the electrolyser reaches the rated temperature in $600 \mathrm{~s}$ and the control system holds the temperature around the optimal operation zone. The electrolyser then operates at a constant power level until the control system determines that the tank level reaches $100 \%$. At this point the electrolyser is switched off both in Scenario 1 and Scenario 2 as it can be observed in Fig. 14.

In Fig. 15(a), the ripples in the stack temperature evolution are because of the electrolyser cooling system. The temperature fluctuates between $57^{\circ} \mathrm{C}$ and $60{ }^{\circ} \mathrm{C}$ due to the hysteresis control logic. 

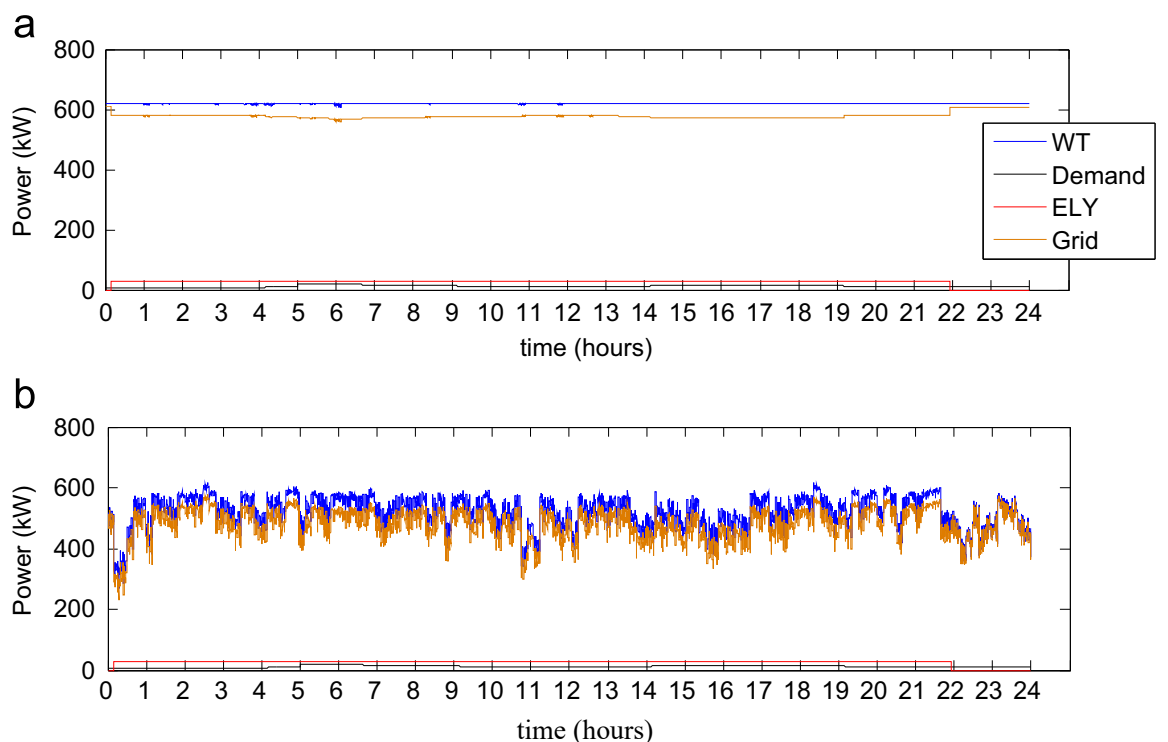

Fig. 14. Simulation results under High wind scenarios, (a) Scenario 1 and (b) Scenario 2. ELY: Electrolyser power; Demand: demand of the HO building; Grid: electrical power exported to the grid; WT: Wind turbine power.
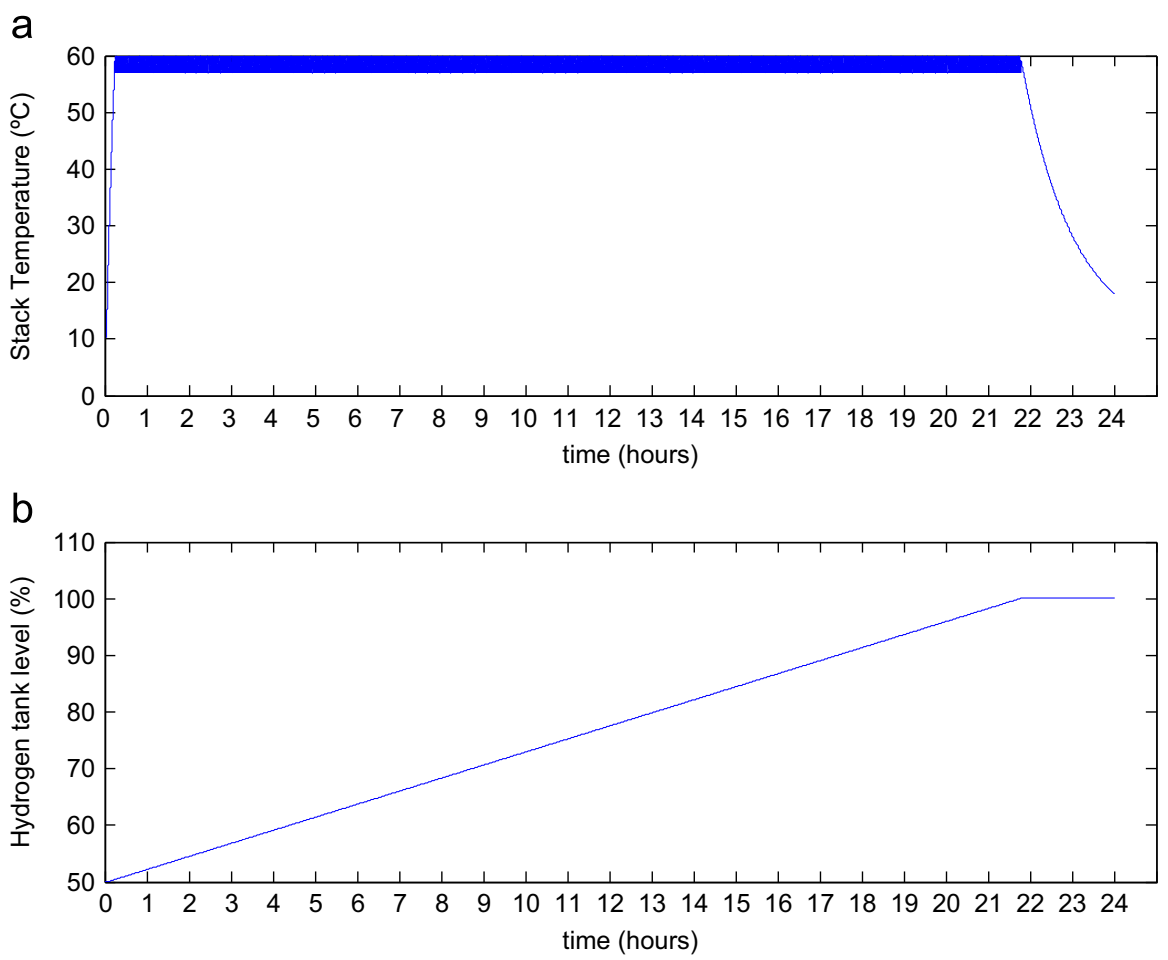

Fig. 15. (a) Electrolyser stack temperature and (b) hydrogen storage tank level during the simulation of Scenario 1 and Scenario 2.

The hydrogen tank level, shown in Fig. 15(b), which is identical for both scenarios, is a result of the balance between electrolyser production and fuel cell hydrogen required during the day. A starting level of $50 \%$ has been assumed in the simulation. The Electrolyser delivering pressure is about 12 barg. However, tank working pressure is given by equation (23) [5]. As it was expected, in windy days the tank is filled in both scenarios since the fuel cell is not used. 


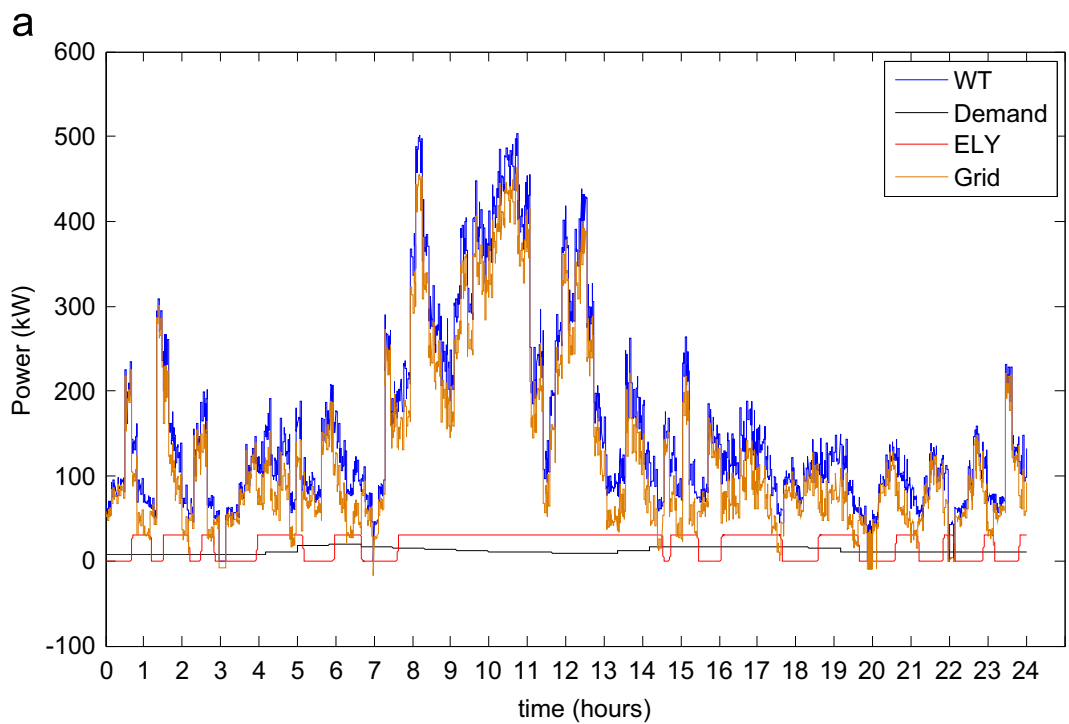

b

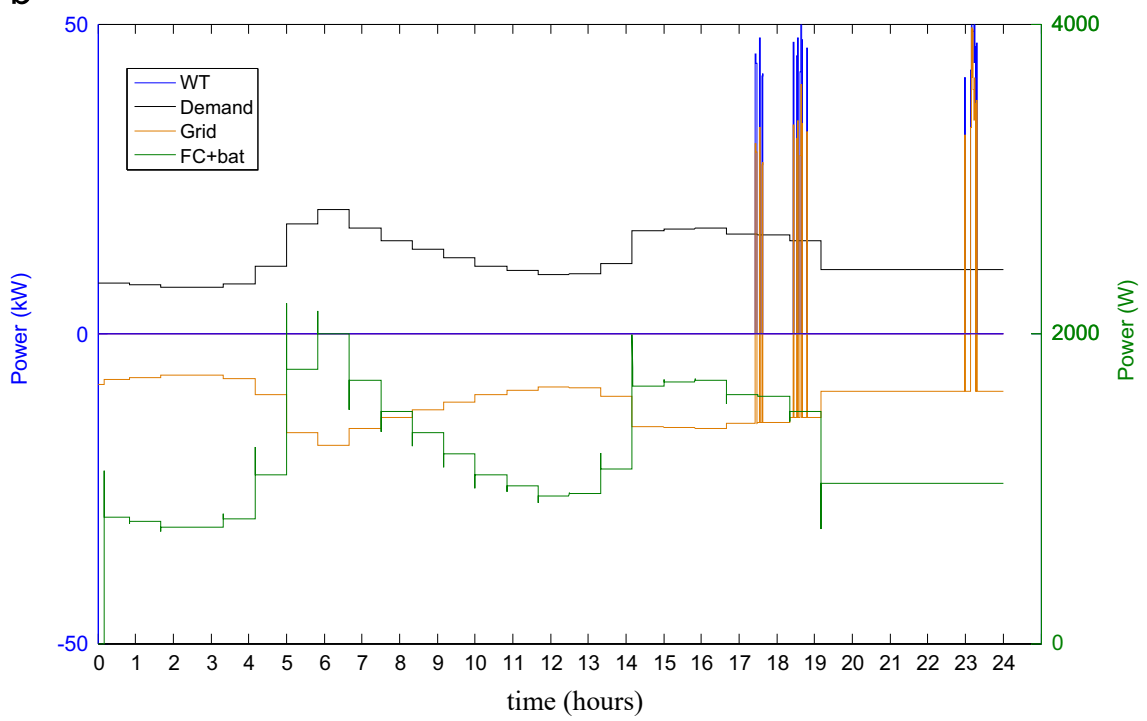

Fig. 16. Simulation results under "scarce wind" scenarios, (a) Scenario 3 and (b) Scenario 4. ELY: Electrolyser power; Demand: demand of the HO building; Grid: electrical power exported to the grid; WT: Wind turbine power; FCpbat: fuel cell (and associated batteries) power represented at second yaxis (For interpretation of the references to colour in this figure, the reader is referred to the web version of this article.).

\subsection{Scenario 3 and Scenario 4: Scarce wind and fuel cell operation}

The performance of the wind--hydrogen model is then evaluated for the scarce wind resource scenarios as illustrated in Fig. 16(a) and (b). These simulations have been specifically carried out to check out the fuel cell operation performance during little or no wind energy availability, and the electrolyser intermittent operation. From the simulations shown in Fig. 16(a) and (b), it can be observed that the electrolyser is activated whenever there is enough excess power from the WT. The abrupt wind profile of "Scenario 3" causes the equipment frequent switch on and off. In contrast, in "Scenario 4" shown in Fig. 16(b), the electrolyser is not activated. The wind resource is very limited and therefore the fuel cell has to be used.

According to the control strategy, the fuel cell is activated in the "Scenario 4" to power the office's ground floor. It should be noted that during the first $10 \mathrm{~min}$, the control system evaluates if the average power from the WT is less than $20 \mathrm{~kW}$ over 10 min, during the course of this $10 \mathrm{~min}$, the demand is taken temporally from the grid. After this period, the fuel cell is activated producing the required power (represented at the second y-axes shown in green colour). During the second part of Scenario 4 (after $17 \mathrm{~h}$ ), the wind starts to blow. However, is not stable enough and powerful enough to stop the fuel cell (the fuel cell is switched off if the average WT power is higher than $60 \mathrm{~kW}$ for $10 \mathrm{~min})$. 

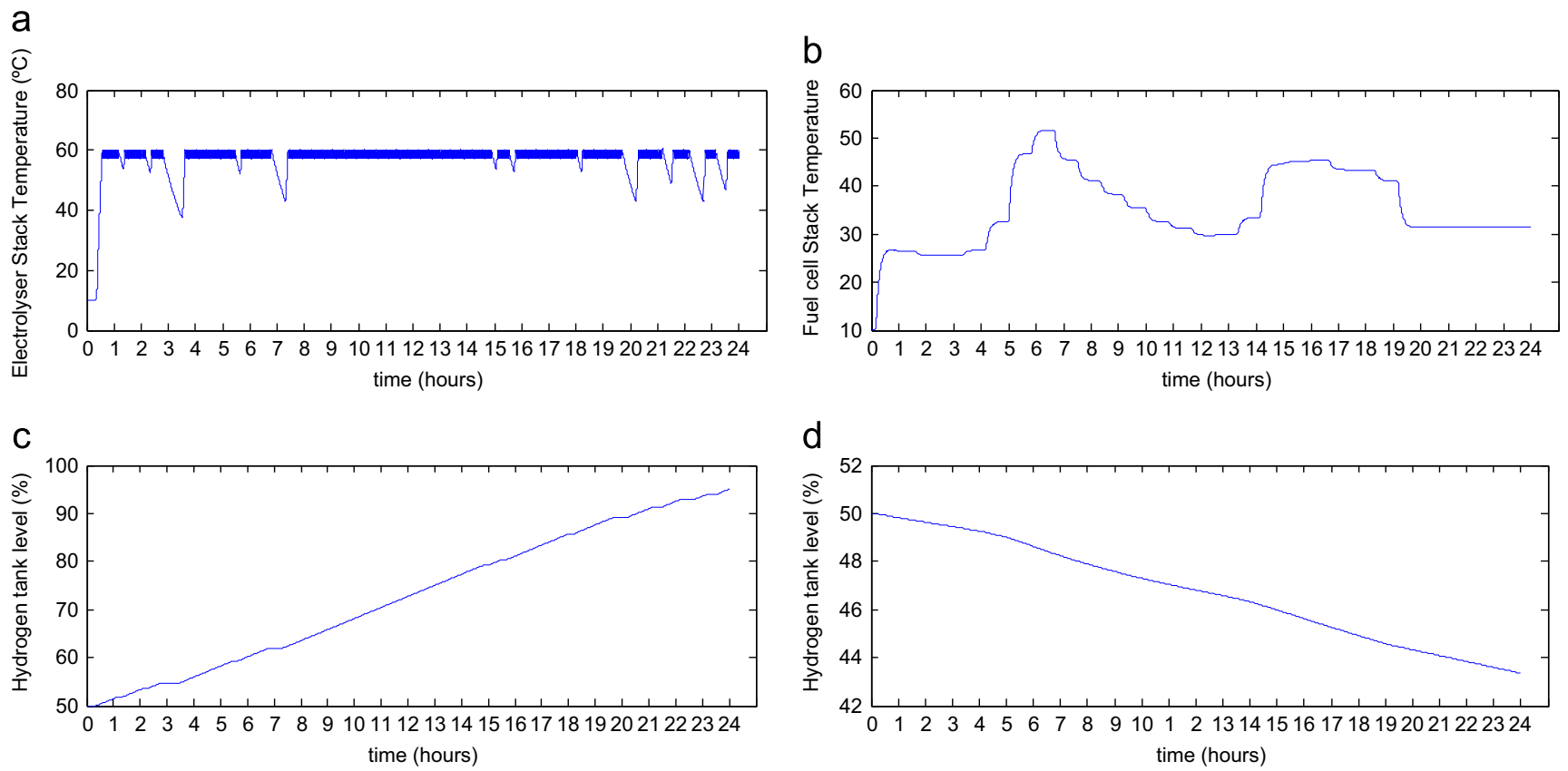

Fig. 17. (a) Electrolyser stack temperature in Scenario 3, (b) Fuel cell stack temperature in Scenario 4, (c) and (d) Hydrogen storage tank levels during the simulation of Scenario 3 and Scenario 4.

Table 11

Performance assessment HO operation in "Scenario 1" to "Scenario 4".

\begin{tabular}{|c|c|c|c|c|c|c|c|c|c|}
\hline Scenario & ${ }^{-} v(\mathrm{~m} / \mathrm{s})$ & $W_{\text {WT }}(\mathrm{MW} \mathrm{h})$ & $W_{\mathrm{EZ}}(\mathrm{kW} \mathrm{h})$ & Wfc (kW h) & $\mathrm{H}_{2} \operatorname{tank}(\%)$ & Ez_on/off & FC_on/off & Autonomous (\%) & $\eta(\%)$ \\
\hline 2 & 11.40 & 12.50 & 652.50 & 0 & 100 & 1 & 0 & 100 & 60.77 \\
\hline 3 & 6.62 & 3.78 & 452.11 & 0 & 92.31 & 13 & 0 & 95.01 & 60.75 \\
\hline
\end{tabular}

Notice that in Fig. 16(b) the power supplied by the fuel cell slightly differs from the power demand, this is because of the fuel cell slow time constant. The batteries supply the transient load while the fuel cell reaches the nominal conditions. The Fuel cell dynamics are also reflected in Fig. 17(b) which shows the varia-tions in the fuel cell stack temperature with the load changes. It should also be noted that the wind velocity is below the WT cut in speed during most of the simulation and that is why the WT produces power only at the end of the simulation, when the wind velocity is higher than $4 \mathrm{~m} / \mathrm{s}$ (cut in speed).

The hydrogen tank level, shown in Fig. 17(c) and (d), is explained by the electrolyser intermittent operation and the fuel cell power production during "Scenarios 3" and " 4 ". The hydrogen consumed by the fuel cell causes the hydrogen tank level to decrease according to power production, and the fuel cell perfor-mance, till $43 \%$. The fuel cell would therefore be able to power the offices for several days without the presence of wind (or with very little presence), till a lower threshold of $30 \%$.

The fuel cell provides only the office ground floor' electrical demand, while most of the buildings' electrical demand is satisfied by the energy imported from the main grid as it can be seen by the negative values of grid power in Fig. 16(b). From the simulation it can be seen that after $17 \mathrm{~h}$, when the wind starts blowing, the grid exports the difference between the power demanded and the power produced by the WT (positive values of grid power).

\subsection{Discussion of results}

This section aims to provide a quantitative analysis and discussion of the $\mathrm{HO} \mathrm{Wind} / \mathrm{H}_{2}$ system performance using the developed complete system model. The performance evaluation will be carried out through using Key Performance Indicators (KPIs) defined in this work. The KPI proposed to evaluate the Wind/ $\mathrm{H}_{2}$ system are: 
1. Average wind speed: $\bar{v}(\mathrm{~m} / \mathrm{s})$.

2. Wind turbine production: WWT (MW h).

3. Energy consumed by the electrolyser: WEZ (kW h).

4. Fuel cell production: Wfc $(\mathrm{kW} \mathrm{h})$.

5. Final tank level: $\mathrm{H}_{2}$ tank (\%).

6. Electrolyser switching on and switching off: Ez_on/off

7. Fuel cell switching on and switching off: $\mathrm{Fc} \_$onf/off

8. Percentage of building demand satisfied by system own resources (WT and Fuel cell): Autonomous (\%)

9. Round trip efficiency of the hydrogen path: $\eta(\%)^{1 / 4} \eta_{\mathrm{ely}} \cdot \eta_{\mathrm{fc}}$ (With efficiencies of electrolyser and fuel cell referred to low heating value without BoP. If either electrolyser or fuel cell is used, the round trip efficiency is equal to the electrolyser efficiency or the fuel cell efficiency, respectively).

The numerical results of the KPI for the four Scenarios are presented through Table 11. A distribution of the wind turbine energy usage is shown in Fig. 18.

a

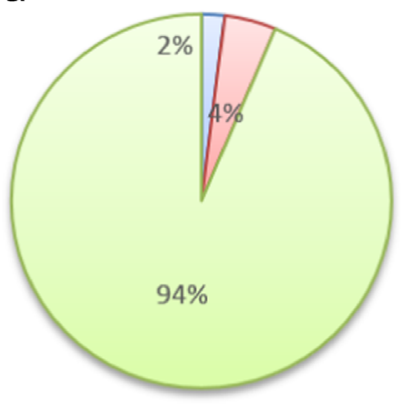

C

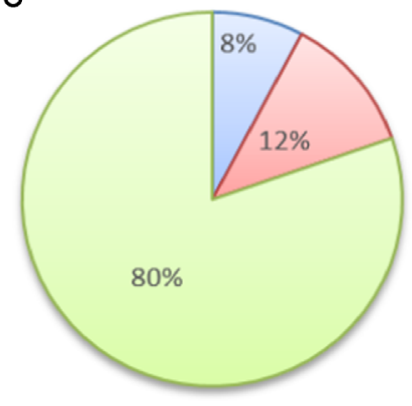

b

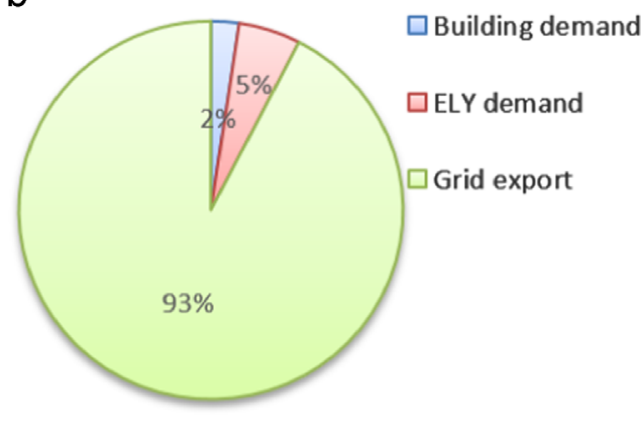

d

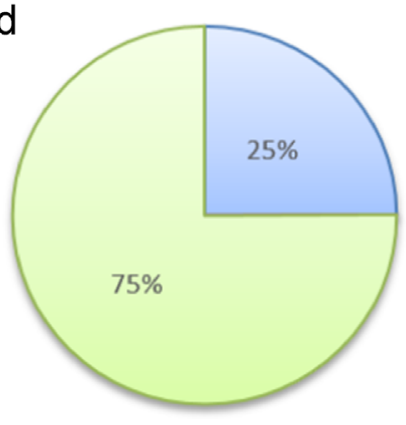

Fig. 18. Wind turbine usage in "Scenario 1" to "Scenario 4", figures (a)-(d) respectively.

The performed analysis for the HO system has showed the following:

- The system ability to operate autonomously, which defines in great part the quality of the design, sizing and efficient operation. As shown in Table 11, in a typical windy day, the system can achieve almost full autonomous operation.

- The on-off switching of the electrolyser is relatively high due to wind power stochastic behaviour. This in turn causes temperature fluctuations in the electrolyser and sometimes its operation out of nominal conditions.

- The electrolyser fills the $\mathrm{H}_{2}$ tank very quickly due to the availability of the wind resource. This means that on many days the electrolyser won't need to be switched on, as the tank is full.

- The fuel cell installed in the HO does not consume all the hydrogen in the tank, therefore the tank level remains high enough even in low wind scenarios. Thus, the extra hydrogen stored could be a potential source of revenue.

- A big proportion of the wind energy is exported to the grid in windy days. This fact has to be taken into account in the grid node power transfer capacity.

- The Round-trip efficiency for this system confirmed that the electrolyser and fuel cell efficiencies are within range of similar projects. An improved thermal insulation, or utilising CHP can further improve the system efficiency. 


\section{Conclusions and future work}

In this paper, a comprehensive modelling methodology that simulates the behaviour of wind-hydrogen energy systems has been presented. A balanced mathematical model that encompasses both dominant dynamics accuracy and low computationalrequirements has been developed. A systematic procedure for parameter estimation and model validation has been provided. The dynamic behaviour of the Wind/H2 system model has been tested by performing the simulations in different wind conditions, using the "Hydrogen Office" plant (as the case study). The model outputs confirmed that the model successfully depict the system behaviour of the Hydrogen Office. Validation showed an average error of less than $2 \%$ in dynamic behaviour. Therefore, it is confirmed that the developed model is a reliable tool in predicting the performance of wind-hydrogen energy systems. The in-deep analysis of the Wind/H2 system performance has enabled the identification of the strengths and weaknesses points of the system performance. Dif-ferent Key Performance Indicators were defined to analyse the $\mathrm{Wind} / \mathrm{H}_{2}$ system operation. For future work, it is recommended to upgrade the model towards a technoeconomic one.

In summary, the model developed within this paper has proved to be a reliable tool for the performance evaluation and optimisation of wind-hydrogen plants. Accurate modelling of such plants behaviour informs future plants building, control and operation. It is therefore expected that this work will help researchers to run scenario analysis, verify theoretical findings, and optimise system operation in future research.

\section{Acknowledgements}

We would like to express our gratitude to the "Bright Green Hydrogen" for providing the needed information and allowing our access to their facilities, without which, this work would have not been possible.

We would also like to express our appreciation to the reviewers for their comments that have contributed to the paper improvement.

\section{Appendix A. Summary of model equations}

\begin{tabular}{|c|c|c|c|}
\hline & Voltage-current relationship & Thermal equations & Hydrogen production/consumption/balance \\
\hline a) & $\begin{array}{l}U_{\text {cell }}=U_{\text {rev }}+\frac{r}{A} I_{s t}^{e z}+s \log \left(\frac{t}{A} I_{s t}^{e z}+1\right) \\
\dot{W}=N I_{s t}^{e z} U_{\text {cell }} \\
U_{\text {rev }}=\frac{\Delta G}{z F} \\
r(T)=r_{0}+r_{1} T \\
t(T)=t_{0}+t_{1} T+t_{2} T^{2}\end{array}$ & $\begin{array}{l}C t_{e z} \frac{d T_{e z}}{d t}=\dot{Q}_{g e n}-\dot{Q}_{\text {cool }}-\dot{Q}_{\text {loss }} \\
\dot{Q}_{g e n}^{e z}=N V_{s t}^{e z} I_{s t}^{e z}\left(1-\eta_{e}\right) \\
Q_{\text {loss }}=\frac{1}{R_{t}}\left(T_{s t}^{e z}-T_{\text {ambient }}\right)+ \\
\quad+h_{f}^{e z}\left(T_{s t}^{e z}-T_{\text {ambient }}\right)+ \\
\quad+h_{n}^{e z}\left(T_{s t}^{e z}-T_{\text {ambient }}\right)\end{array}$ & $\begin{array}{l}\dot{m}_{H_{2}}=\eta_{F} \frac{N I}{z F} \\
\eta_{F}(\rho, T)=f_{2}(T) \frac{\rho^{2}}{\rho^{2}+f_{1}(T)}\end{array}$ \\
\hline b) & 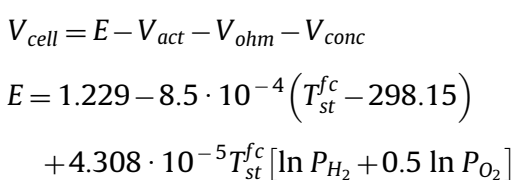 & $\begin{array}{l}C_{t}^{f c \frac{d T_{\text {st }}^{f c}}{d t}}=\dot{Q}_{H_{\text {reac }}}-P_{\text {elec }}-\dot{Q}_{a m b} \\
\dot{Q}_{H_{\text {reac }}}=\frac{-\Delta H_{\text {reac }} \cdot I_{f c}}{2 F}\end{array}$ & $\dot{n}_{f c}=\frac{n_{\text {cells }}^{l_{s t}^{2 z}}}{z \mathrm{~F}}$ \\
\hline & $\begin{array}{l}V_{a c t}=x_{1}-8.5 \cdot 10^{-4}\left(T_{s t}^{f c}-298.15\right)+ \\
+4.308 \cdot 10^{-5} T_{s t}\left[\ln P_{H_{2}}+0.5 \ln P_{O_{2}}\right]+ \\
+\left[\begin{array}{l}\left(x_{2} T_{s t}^{f c}+x_{3}\right) P_{O_{2}}^{2}+\left(x_{4} T_{s t}^{f c}+x_{5}\right) P_{O_{2}}+ \\
+\left(x_{6} T_{s t}^{f c}+x_{7}\right)\end{array}\right]\end{array}$ & $\dot{Q}_{a m b}=\left(h_{c}^{f c}+h_{n}^{f c}\right) \cdot\left(T_{s t}^{f c}-T_{a m b}\right)$ & \\
\hline & $\begin{array}{l}V_{\text {ohm }}=\frac{I_{s t}^{f c} \cdot t_{m}}{x_{9}\left(\frac{1}{303}-\frac{1}{T_{s t}^{f c}}\right)} \\
V_{\text {conc }}=I_{s t}^{f c}\left[\left(x_{10} T_{s t}^{f c}+x_{11} P_{O_{2}}\right) \frac{f_{s t}^{f c}}{x_{12}}\right]^{x_{13}}\end{array}$ & $P_{\text {elec }}=V_{f c} I_{f c}$ & \\
\hline c) & & & $\dot{m}_{t k}=\dot{m}_{e l y}-\dot{m}_{f c}-\dot{m}_{l e a k}$ \\
\hline
\end{tabular}

(a) Electrolyser model, (b) Fuel cell model and (c) Hydrogen tank model. 


\section{References}

[1] Hesaraki A, Holmberg S, Haghighat F. Seasonal thermal energy storage with heat pumps and low temperatures in building projects-A comparative review. Renew Sustain Energy Rev 2015;43:1199-213.

[2] Parameshwaran R, Kalaiselvam S, Harikrishnan S, Elayaperumal A. Sustainable thermal energy storage technologies for buildings: a review. Renew Sustain Energy Rev 2012;16:2394-433.

[3] Rismanchi B, Saidur R, Boroumandjazi G, Ahmed S. Energy, exergy and environmental analysis of cold thermal energy storage (CTES) systems. Renew Sustain Energy Rev 2012;16:5741-6.

[4] Gazey R, Ali D, Aklil D. Real world renewable hydrogen transport. Lifesci Global 2012;1:14-22.

[5] Argumosa MdP, Chacon E, Schoenung SM. Evaluation of integrated hydrogen systems: IEA Task 18. Int J Hydrog Energy 2010;35:10031-7.

[6] Valverde L, Ali D, Abdel-Wahab M, Guerra J, Hogg DF. A technical evaluation of wind-hydrogen $(\mathrm{WH})$ demonstration projects in Europe. In: Proceedings of the 2013 fourth international conference on power engineering, energy and electrical drives (POWERENG). 2013: p. 1098-1104.

[7] Gahleitner G. Hydrogen from renewable electricity: an international review of power-to-gas pilot plants for stationary applications. Int J Hydrog Energy 2013;38:2039-61.

[8] Eide PO, Hagen EF, Kuhlmann M, Rohden R. Construction and commissioning of the Utsira wind/hydrogen stand-alone power system. In: Proceedings of the EWEC 2004-European wind energy conference.

[9] Nakken T, Frantzen E, Hagen EF, Strøm H. Utsira demonstrating the renewable hydrogen society. In: Proceedings of the WHEC16- world hydrogen energy conference 2006.

[10] Gammon R, Roy A, Barton J, Little M. HARI-hydrogen and renewables integration. Case study report. IEA Hydrogen Implementing Agreement 2006.

[11] F.J. Pino, Análisis de Sistemas Integrados de Producción de Hidrógeno a parti de Energía Eólica. Aportaciones al modelado dinámico de sistemas (Ph.D. Dissertation), 2010, Sevilla, Spain: Universidad de Sevilla, http://dx.doi.org/ http://fondosdigitales.us.es.

[12] Gazey R, Salman SK, Aklil-D'Halluin DD. A field application experience of integrating hydrogen technology with wind power in a remote island location. J Power Sources 2006;157:841-7.

[13] Pedrazzi S, Zini G, Tartarini P. Modelling and simulation of a wind-hydrogen CHP system with metal hydride storage. Renew Energy 2012;46:14-22.

[14] Khan MJ, Iqbal MT. Analysis of a small wind-hydrogen stand-alone hybrid energy system. Appl Energy 2009;86:2429-42.

[15] Onar OC, Uzunoglu M, Alam MS. Dynamic modeling, design and simulation of a wind/fuel cell/ultra-capacitor-based hybrid power generation system. J Power Sources 2006;161:707-22.

[16] Raju M, Khaitan SK. System simulation of compressed hydrogen storage based residential wind hybrid power systems. J Power Sources 2012;210:303-20.

[17] Zhou T, Francois B. Modeling and control design of hydrogen production process for an active hydrogen/wind hybrid power system. Int J Hydrog Energy 2009;34:21-30.

[18] Kélouwani S, Agbossou K, Chahine R. Model for energy conversion in renewable energy system with hydrogen storage. J Power Sources 2005;140:392-9.

[19] Valverde L, Rosa F, del Real AJ, Arce A, Bordons C. Modeling, simulation and experimental set-up of a renewable hydrogen-based domestic microgrid. Int J Hydrog Energy 2013;38:11672-84.

[20] Onar OC, Uzunoglu M, Alam MS. Modeling, control and simulation of an autonomous wind turbine/photovoltaic/fuel cell/ultra-capacitor hybrid power system. J Power Sources 2008;185:1273-83.

[21] Pino FJ, Valverde L, Rosa F. Influence of wind turbine power curve and electrolyzer operating temperature on hydrogen production in wind-hydrogen systems. J Power Sources 2011;196:4418-26.

[22] Ulleberg Ø. Modeling of advanced alkaline electrolyzers: a system simulation approach. Int J Hydrog Energy 2003;28:21-33.

[23] Ali D, Aklil-D'Halluin DD. Modeling a Proton Exchange Membrane (PEM) Fuel Cell System as a Hybrid Power Supply for Standalone Applications. Power and Energy Engineering Conference (APPEEC), 2011 Asia-Pacific 2011:1-5.

[24] Ali DM, Salman SK. Investigation into Modelling of a fuel cell stack system. In: Proceedings of the 2006 UPEC '06 41st international 2006 universities power engineering conference; 1 : p. 137-141.

[25] Sánchez JA, Veganzones C, Martínez S, Blázquez F, Herrero N, Wilhelmi JR. Dynamic model of wind energy conversion systems with variable speed synchronous generator and full-size power converter for large-scale power system stability studies. Renew Energy 2008;33:1186-98.
[26] Martins M, Perdana A, Ledesma P, Agneholm E, Carlson O. Validation of fixed speed wind turbine dynamic models with measured data. Renew Energy 2007;32:1301-16.

[27] Hogg D. Modelling and Optimisation of the Hydrogen Storage System at the Hydrogen Office. Heriot-Watt University; 2011.

[28] Pukrushpan JT, Stefanopoulou AG, Huei Peng. Modeling and control for PEM fuel cell stack system. In: Proceedings of the American Control Conference; vol. 4:4, 2002. p. 3117-22.

[29] Pukrushpan JT, Stefanopoulou AG, Peng H. Control of Fuel Cell Power Systems. Springer; 2004.

[30] Hashem Nehrir M, Wang C. Modeling and Control of Fuel Cells. Piscataway, USA: IEEE; 2009.

[31] Al-Baghdadi MARS. Modelling of proton exchange membrane fuel cell perfor-mance based on semi-empirical equations. Renew Energy 2005;30:1587-99.

[32] EG\&G TS. Fuel Cell Handbook (Seventh Edition); 2004.

[33] Diéguez PM, Ursúa A, Sanchis P, Sopena C, Guelbenzu E, Gandía LM. Thermal performance of a commercial alkaline water electrolyzer: experimental study and mathematical modeling. Int J Hydrog Energy 2008;33:7338-54.

[34] Laurencelle F, Chahine R, Hamelin J, Agbossou K, Fournier M, Bose TK, et al. Characterization of a Ballard MK5-E proton exchange membrane fuel cell stack. Fuel Cells 2001;1:66-71. 